\title{
¿Por qué estudiar los movimientos sociales hoy? Apuntes subterráneos para la interculturalidad más allá de lo étnico
}

Pedro Rojas-Oliveros ${ }^{*}$

Artículo recibido: 16 de diciembre de 2013

Artículo aprobado: 3 de abril de 2014

Doi: dx.doi.org/10.12804/desafios26.1.2014.04

Para citar este artículo: Rojas-Oliveros, P. (2014). ¿Por qué estudiar los movimientos sociales hoy? Apuntes subterráneos para la interculturalidad más allá de lo étnico. Desafíos, 26 (1), 121-169. doi: dx.doi.org/10.12804/desafios26.1.2014.04

\section{Resumen}

Las prácticas interculturales suelen asociarse con acciones de interlocución entre grupos étnicamente diferenciados, principalmente cuando se trata de actividades en torno a la educación o a la investigación. Este traslape entre lo étnico y lo cultural ha propiciado una suerte de clausura del proyecto de la interculturalidad, al velar los discursos de otros grupos sociales subalternos, que encuentran el sustento de su (re)definición identitaria más allá del capital étnico. El estudio de los movimientos sociales contemporáneos facilita la visibilización de esos discursos y sus posibilidades de articulación con otras maneras subalternizadas de ver y resolver el mundo. La apertura del proyecto intercultural es urgente para la deconstrucción de los modelos hegemónicos coloniales en todo campo, desde lo económico hasta lo político, pasando necesariamente por lo epistémico. La contracultura, como respuesta a una imposición de valores y saberes,

\footnotetext{
* Maestrando en Antropología Social de la Universidad Nacional de Colombia. Politólogo de la Universidad del Rosario, joven investigador y docente de las facultades de Ciencia Política y Gobierno, y Relaciones Internacionales de la misma universidad. Correo electrónico: rojaso.pedro@gmail.com
} 
ofrece una posibilidad poco estudiada de resistencia y acción politica desde las márgenes sociales. Por medio del acercamiento teórico a diferentes propuestas de estudio de los movimientos sociales y los productos de un seminario de investigación dictado en la Universidad del Rosario, con el artículo se pretende aportar algunas pistas sobre la posibilidad de articulación entre identidades diferenciadas y la apertura del proyecto intercultural consecuente.

Palabras clave: movimientos sociales, articulación, interculturalidad, identidades, contracultura

\title{
Why Study Social Movements Today? Underground Notes for Interculturalism beyond the Ethnic
}

\begin{abstract}
Intercultural practices are usually associated with actions for dialogue between different ethnic groups, especially when it comes to activities around education or research. This overlap between ethnicity and culture has led to a kind of closure of the political project of interculturalism, cover the speeches of other subaltern social group who encounter the of support of their (re) definition of identity beyond ethnicity redefinition. The judicious study of contemporary social movements allows for the visualization of those speeches and for the possibilities articulation with other competing ways of seeing and solving the world. The opening of an intercultural political project is urgent for the deconstruction of hegemonic models in every field, from the economic to the political, necessarily going through the epistemic. The counterculture as a response to the imposition of values and knowledge provides a possibility understudied of resistance and political action from the social margins. Through a theoretical approach to different relevant proposals of social movements and the results of a research seminar given at the Rosario University, the article seeks to provide some clues about the possibility of articulation between different identities and the opening of the intercultural project.
\end{abstract}

Key words: social movements, intercultural practice, identities, counterculture 


\title{
Por que estudar os movimentos sociais hoje? Anotações subterrâneas para a interculturalidade além do étnico
}

\begin{abstract}
Resumo
As práticas interculturais são habitualmente associadas a ações de interlocução entre grupos etnicamente diferenciados, principalmente quando se trata de atividades em torno à educação ou à pesquisa. Esta sobreposição entre o étnico e o cultural tem propiciado um tipo de clausura do projeto da interculturalidade, velando os discursos de outros grupos sociais subalternos, que encontram o sustento de sua (re)definição identitária, além do capital étnico. O estudo criterioso dos movimentos sociais contemporâneos permite a visibilidade desses discursos e suas possibilidades de articulação com outras formas subalternizadas de ver e resolver o mundo. A apertura do projeto intercultural é urgente para a desconstrução dos modelos hegemônicos coloniais em todo âmbito, desde o econômico até o político, passando necessariamente pelo epistêmico. A contracultura, como resposta a uma imposição de valores e saberes, oferece uma possibilidade pouco estudada de resistência e ação politica desde as margens sociais. Por meio da aproximação teórica a diferentes propostas de estudo dos movimentos sociais e os produtos de um seminário de pesquisa ditado na Universidade, o artigo pretende apenas aportar algumas pistas sobre a possibilidade de articulação entre identidades diferenciadas e a apertura do projeto intercultural como consequência do anterior.
\end{abstract}

Palavras- chave: Movimentos sociais, articulação, interculturalidade, identidades, contracultura 
La blasfemia requiere que un [o] se tome las cosas muy en serio. Donna Haraway (2013, p. 1)

Contra de las élites vegetales. En comunicación con el suelo. Oswald de Andrade (2013, p. 3)

\section{Preludio}

Todo lo que ves

Es que esto no es lo que es. Control Machete (2003, pista 3)

Las páginas que siguen son producto de algunos años en torno a la discusión de los denominados Nuevos Movimientos Sociales (NMS). Para discutir, claro, se necesita polifonía; por esa razón, es oportuno decir que, aunque la responsabilidad de lo que de aquí en adelante se exprese es mía, los argumentos están construidos a manera de quilt ${ }^{1}$ no como metodología predeterminada, sino por esa naturaleza tanto del "objeto de estudio" como de las discusiones que suscita. No se trata solo de disertaciones entre autores, personas expertas y militantes, pues la mayoría de las reflexiones nacen en el marco del seminario de investigación Movimientos sociales y luchas políticas, de las facultades de Ciencia Política y Gobierno y Relaciones Internacionales de la Universidad del Rosario, del cual formo parte desde 2008 en diferentes roles. El trabajo juicioso de un grupo de estudiantes de esas facultades, ha permitido recrear un mapa más detallado sobre la movilización social contemporánea en Colombia y también conocer las motivaciones, equivalencias, expectativas y al final identificaciones con las que se constituyen y estudian los movimientos sociales. ${ }^{2}$

\footnotetext{
1 Colcha de retazos. Es una metodología empleada en algunas actividades de trabajo colectivo, sobre todo en torno a la (re)construcción de memoria de hechos violentos. Lo que se pretende en esos ejercicios y en este texto es evidenciar la polifonía de apreciaciones, propuestas y juicios sobre eventos o discursos que afectan a los integrantes de un grupo humano. El resultado supone la construcción de un punto de vista a partir de la articulación entre diversos enfoques.

2 El seminario funciona como materia electiva y de énfasis. Es dirigido por la profesora Ángela Santamaría y tiene dos componentes: uno práctico y uno teórico, este último coordinado por mí. Durante el semestre, los y las estudiantes desarrollan un proyecto de investigación sobre un tema de libre elección relacionado con la acción colectiva en Colombia, de acuerdo
} 
Este texto presenta algunos de los apuntes recogidos en ese marco, desde dos ejes:

1) El discurso intercultural promovido por algunas organizaciones sociales étnicas como proyecto decolonial.

2) La emergencia de un difuso movimiento contracultural como alternativa de representación política.

Estos apuntes no tienen pretensión diferente a la de aportar algunos elementos teóricos, metodológicos e historiográficos al debate sobre el estudio de las identidades a partir de una posibilidad de diálogo entre dos que se suponen tan lejanas: las étnicas y las contraculturales. Más allá de establecer unas posibles coincidencias en sus emergencias, definiciones o luchas, intento dar respuesta a las preguntas: ¿podemos hallar en los procesos de subalternización de ciertas identidades — diferentes y diferenciadas - posibilidades y/o condiciones de articulación? ¿Es posible construir un proyecto intercultural más allá de lo étnico? ¿'Tiene el movimiento contracultural algo que aportar en las luchas sociales contrahegemónicas y decoloniales?

Hablar de contracultura tiene su grado de complejidad. A menudo es considerado un asunto marginal, poco relevante, apenas del fuero de una etapa de la vida en la que los y las jóvenes tienen un comportamiento reactivo basado en una música estridente, una estética agresiva y un estilo de vida transgresor y subterráneo. Al ser definida por oposición, la contracultura se aprecia como mera respuesta mas no como "posibilidad de". Habitualmente los medios de comunicación masivos y algunos académicos hacen un paralelo entre las denominadas "tribus urbanas" y la contracultura apelando a mínimas referencias estéticas o de comportamiento, lo que genera la activación de estereotipos que, según Hall (2010), determinan las relaciones de poder, al reducir "a

con las herramientas metodológicas y conceptuales construidas en clase. El seminario es también semillero de la línea de investigación Acción colectiva indígena, del Observatorio de Redes y Acción Colectiva (ORAC) del Centro de Estudios Políticos e Internacionales (CEPI) de la Universidad. Los trabajos de grado (monografías, estudios de caso, disertaciones) dirigidos por los profesores de la clase forman parte del eje temático del seminario y de la línea de investigación. 
unos pocos rasgos esenciales y fijos" todo un entramado histórico mutable. Situarse en esos rasgos estéticos mantiene la relación de subalternidad como ocurre con la cultura popular o las minoritarias. Hoy día, son habituales las referencias al movimiento contracultural como que este apenas sirve como dispositivo de repetición de los estilos de vida del primer mundo, incrementa el consumismo, vacía de contenido las identidades locales y contribuye a la violenta relación centro-periferia (Heath y Potter, 2005).

Entrar a debatir cada uno de estos planteamientos, considero, sería alimentar uno de ellos: la contracultura solo se define como respuesta/ negación. Por el contrario, pretendo mostrar ciertas pistas que inducen a pensar que "las cosas del mundo (prácticas, entidades, ideas, etc.) son el resultado de las relaciones que las constituyen", es decir, "el conjunto de articulaciones significativas para comprender la especificidad de una cosa en el mundo es la manera en que se define su contexto" (Restrepo, 2011, p. 14). Crear contexto sobre la forma como emerge aquello que se denomina como contracultura en el plano global y en el local no solo permite poner en cuestión esas relaciones de poder basadas en prejuicios, sino también situar las posibilidades de articulación entre esta cultura y otras también subalternizadas.

Se han hecho varios esfuerzos para abordar el tema de la contracultura desde el campo académico: como fenómeno histórico (Roszack, 1968; Goffman, 2005), como protesta (Marroquín, 1975), como negocio (Heath y Potter, 2005) y como cultura alternativa (Savater, 1989) son los que más destacan. Sin embargo, el trabajo que marca el derrotero de mi propuesta es el de Andrea Restrepo Restrepo (2010) sobre el surgimiento del movimiento punk en la ciudad de Medellín y su tarea subterránea de crear, por medio de la música, nuevos espacios como tercería al antagonismo narcotráfico-institucionalidad de la década del ochenta: prácticas políticas, nociones de estética, prácticas económicas y, sobre todo, como posibilidad de inscribir otras narrativas sobre fenómenos y lugares concretos en la historia nacional.

Con frecuencia, la producción académica se refiere a la interculturalidad como alternativa al multiculturalismo y su supuesta conni- 
vencia con el capitalismo contemporáneo. ${ }^{3}$ Para quienes defienden esta premisa, la diferencia fundamental entre el multiculturalismo y la interculturalidad es que el primero surge "desde" las instituciones del Estado a manera de política pública de reconocimiento y control social, mientras la segunda lo hace "desde" las bases de las organizaciones étnicas (en el caso andino, en especial las indígenas) y se erigen como proyecto político contrahegemónico:

Su proyecto no es simplemente reconocer, tolerar o incorporar lo diferente dentro de la matriz y estructuras establecidas. Por el contrario, es implosionar — desde la diferencia — en las estructuras coloniales del poder como reto, propuesta, proceso y proyecto; es re-conceptualizar y re-fundar estructuras sociales, epistémicas y de existencias que ponen en escena y en relación equitativa lógicas, prácticas y modos culturales diversos de pensar, actuar y vivir (Walsh, 2010, p. 77).

Como lo señala Walsh, la posición antagónica de la interculturalidad como proyecto político frente a discursos hegemónicos racializados, sexuados, economicistas y reduccionistas, es abierta, incluyente y abarca a todos los sujetos individuales y colectivos subalternados por "las estructuras coloniales de poder", al apostar por la subversión de una estructura social y epistémica que mantiene la jerarquía de unos saberes-modos de vida considerados como legítimos y verdaderos, por un lado y, del otro, unos menospreciados, más cercanos al mito y a la pasión que a la certeza de la ciencia eurocentrada.

Sin embargo, hoy día es posible advertir en los trabajos de investigación de los estudios sociales una cierta cooptación del significante interculturalidad por parte de investigadores, activistas y organizaciones sociales para describir, primordialmente, procesos interétnicos. Lo

3 Aunque lejos de la discusión sobre la interculturalidad, el trabajo del filósofo esloveno Slavoj Zizek da buena cuenta de esa relación entre el multiculturalismo y una etapa específica de la economía de mercado. Para este autor, el primero es la forma ideológica contemporánea del segundo (“capitalismo cultural") (1998; 2003; 2007). De manera más reciente y en atención a las especificidades del reconocimiento cultural en algunos países de América Latina, la antropóloga argentina Rita Laura Segato (2007) problematiza esa supuesta connivencia. 
que se advierte es una suerte de traslape entre lo étnico y lo cultural, que clausura la posibilidad de alteridades que encuentran su sustento más allá de lo étnico. De cierta manera, esta clausura ha ocasionado que la interculturalidad opere como una "tecnología de gobierno de la alteridad", descrita por el antropólogo colombiano Axel Rojas (2011) como "un programa que define la manera en que deberían comportarse quienes son pensados como otros de la nación" (p. 175). Enfatizo en que esto ha ocurrido de modo parcial, pues negar o caricaturizar las posibilidades democratizadoras (logradas y prospectadas) en torno al proyecto de la interculturalidad sería un error de mi parte. Lo que intento poner sobre la mesa es la idea de que ese traslape de lo étnico y lo cultural oblitera la posibilidad de incluir en el proyecto político otras culturas, "otras maneras de ver y resolver el mundo" que no necesariamente sustentan sus procesos identitarios en la diferencia étnica. Además, ese traslape-clausura dentro de los estudios sociales termina contribuyendo al control de la diferencia por parte de la institucionalidad. La afirmación suena un tanto imprecisa, pero intentaré darle fuerza y vida en lo que sigue.

¿Qué tiene que ver el estudio de los movimientos sociales en todo esto? Tiene que ver en dos sentidos: en primer lugar, debe entenderse que el proyecto de la interculturalidad es promovido sobre todo por organizaciones sociales étnicas, lo que produce el traslape cultura-etnia mencionado y la clausura del proyecto, como consecuencia. Solo un estudio contextualizado sobre la emergencia y el desarrollo de esas identidades de los movimientos en torno al proyecto intercultural, así como de lo que aquí se propone como movimiento contracultural, posibilita unas condiciones de articulación, es decir, facilita la participación de otras identidades no necesariamente etnizadas y, por ende, la apertura de la clausura. Por estudio contextualizado me refiero al abordaje de lo que Stuart Hall (2003) denominó punto de sutura o articulación "entre las subjetivaciones y las posiciones de sujeto"; en otras palabras, la idea de que la identidad es una articulación en un momento concreto entre: "(1) los discursos ${ }^{4}$ y las prácticas que constituyen las

\footnotetext{
4 Siempre viene bien aclarar que por discurso no debe entenderse algo limitado al habla y a la escritura. Para Ernesto Laclau (2005), "el discurso obedece a un complejo de elementos
} 
posiciones de sujeto (mujer, joven, indígena, etc.) y (2) los procesos de producción de subjetividades que conducen a aceptar, modificar o rechazar estas posiciones de sujeto" (Hall, 2010, citado en Restrepo 2012, p. 140). En segundo lugar, como lo señala Judith Butler (2000):

$[\ldots]$ las nuevas formaciones políticas no tienen una relación analógica entre sí $[\ldots]$. De hecho los momentos más prometedores se producen cuando un movimiento social halla su condición de posibilidad en otro [lo que ubica a la diferencia como] la condición de posibilidad de la identidad o, mejor, su límite constitutivo: lo que hace posible su articulación y, al mismo tiempo, lo que hace posible cualquier articulación final o cerrada (p. 7).

Es decir, situar e historizar la emergencia y la lucha de los movimientos sociales de carácter étnico y la de otros sujetos también subalternados, diferenciarlos, puede conducir a situar también sus posibilidades de identificación y articulación.

En los primeros años del seminario de investigación Movimientos sociales y luchas políticas, nos propusimos como punto de partida, la consolidación de una definición de los NMS. Mediante la lectura de autores como Melucci (1985), Della Porta y Kriesi (2002), Tarrow (2005), Touraine (2006) y Segato (2007), por mencionar algunos, intentamos delimitar lo que es y lo que no es un movimiento social contemporáneo, a partir de la diferencia entre las agrupaciones de clase y gremiales de las décadas del cincuenta al setenta del siglo anterior, por un lado y las de épocas más recientes, por el otro, donde las fronteras clasistas parecen difuminarse (o al menos hemos estado convencidos de ello) ${ }^{5}$ y se demandan soluciones respecto a conflictos de reconocimiento cultural, redefinición identitaria, apertura de lo jurídico, inclusión en la política y se acentúa en la reforma más que en la revolución.

en el cual las relaciones juegan un rol constitutivo" (p. 92). Se trata de una articulación de relaciones sociales diferenciales.

5 Esta idea no debe entenderse como una aceptación de la idea apocalíptica de Fukuyama y damos por superado el conflicto de clases característico de las sociedades capitalistas. Nos referimos a que el punto de identificación de los NMS se sobrepone al discurso clasista y remarca los contextos diversos. 
Sin embargo, rápidamente nos dimos cuenta de que esa distinción no es del todo precisa, pues, al menos en Colombia, es posible encontrar organizaciones que se desplazan de las reivindicaciones gremiales de los movimientos clásicos a los repertorios de acción de los nuevos. ${ }^{6}$ Asimismo, la constante necesidad de realizar estudios interseccionales donde se cruzan el género, la clase y la etnia, por ejemplo, hacen inútil la tarea de posicionar mojones fronterizos inamovibles. ${ }^{7}$ Estas situaciones nos mostraron que, además de buscar una definición más amplia y dinámica de los movimientos sociales, necesitábamos enfoques multi e interdisciplinarios para lograrlo:

Nuestros objetos de estudio se sitúan en el cruce de diferentes disciplinas y problemáticas, exigiéndonos [...] desplazarnos del universo político al jurídico, y del jurídico al cultural. [Esta] complejidad ha implicado que optemos por una aproximación multidisciplinaria (derecho, sociología, ciencia política, relaciones internacionales, estudios culturales), la cual busca tener en cuenta el conjunto de las dinámicas sociales propias del proceso de constitución de la acción colectiva de grupos en los que la "identidad" ocupa un lugar central (Rojas y Santamaría, 2011, p. xvii).

La complejidad que señalo respecto al estudio de los NMS en Colombia reside en que el contexto en donde germinan y se desarrollan está atravesado por la violencia de la que son objeto (los procesos de

\footnotetext{
6 En el segundo semestre de 2013, los estudiantes del programa de Ciencia Política y Gobierno José Saade y María Alejandra Rendón desarrollaron el trabajo de investigación La Mesa Amplia Nacional Estudiantil de la contrarreforma al reflujo: ¿Es la MANE necesaria en el debate de la educación superior? (2011-2013); en él ofrecen una muestra de lo anterior. Mientras la MANE se constituye como una agrupación gremial, las estrategias, los discursos y los repertorios apelan a una serie de novedosas estrategias más cercanas a las caracterizaciones habituales de los NMS.

7 Así lo demuestra, por ejemplo, el trabajo de grado de la internacionalista Laura María Calderón (2012), Análisis del proceso de las redes transnacionales que protegen a defensores de derechos bumanos. Caso: Resolución de la CIDH, medidas provisionales respecto a la República de Colombia, asunto Mery Naranjo y otros (2006-2011), en el que se evidenció la necesidad de una metodología y unos marcos conceptuales amplios para interpretar un sujeto de investigación complejo, objeto de diversos tipos de violencia y exclusión, a la vez que se valió de una variedad de estrategias, repertorios, discursos y simbologías para realizar sus reivindicaciones.
} 
subalternización). No me refiero solo a la violencia de los agentes del monopolio de la fuerza o los actores armados ilegales, sino también a la violencia que esas estructuras coloniales de poder — ya señaladas por Walsh - y sus lenguajes empleados en la cotidianidad de los sujetos subalternizados, dislocan sus relaciones sociales, sus sustentos territoriales y sus visiones del mundo. Por lo anterior, las identidades ocupan un lugar central, pues su redefinición por parte de los colectivos respecto a su condición de subalternidad y su posición respecto a esa condición, constituyen su posibilidad de articulación.

Con el fin de desarrollar y argumentar lo expuesto, he planteado el texto en tres partes. En la primera esbozo la relación entre la crisis de representación política mundial en el crepúsculo del siglo XX, el surgimiento de los NMS y, de manera superficial, los enfoques desde donde se han estudiado, con la intuición de que en estos existe cierta complicidad en lo que he denominado el traslape de lo étnico por lo cultural y la clausura del proyecto de la interculturalidad. En la segunda parte, luego de exponer algunos apuntes sobre lo que puede ser el proyecto', sugiero ampliar el significante de interculturalidad — en tanto desbordamiento de los límites étnicos impuestos por ciertas prácticas académicas - para propiciar el diálogo con otros grupos sociales subalternos. En la tercera parte, a partir del movimiento contracultural, bosquejo la práctica del contextualismo radical como alternativa a la clausura epistémica respecto a los NMS y posibilidad tanto de diálogo como de equivalencia entre diversos proyectos políticos basados en la redefinición de identidades.

\title{
Del telón de acero a la política de identidad
}

\author{
Ya cayó el telón de acero \\ y derribamos el muro de Berlín, \\ $y$ abora todos juntos como hermanos \\ vamos de la mano a comer a un Burger King. \\ Boikot (2000, pista 19)
}

El surgimiento y el desarrollo de los NMS, sobre todo en América Latina, han tenido como característica la contribución, en unos casos más activa que en otros, de académicos que desde la investigación- 
participación han acompañado, visibilizado e incluso criticado las propuestas y los alcances de las organizaciones sociales. El caso de Colombia es bastante representativo: el trabajo de investigadores como Orlando Fals Borda, Martha Rodríguez, Luis Guillermo Vasco, Jaime Arocha, Nina S. de Friedemann, Arturo Escobar o Eduardo Restrepo, por mencionar algunos, ha contribuido a disminuir el abismo entre lo académico y la acción política. Algunas categorías analíticas como las de "afrocolombiano" o "comunidad negra" o algunas propuestas metodológicas como la perspectiva sentipensante han tenido un desplazamiento entre los debates epistémicos y el trabajo de activistas. Debido a su marcado acento en la educación y su intención de deconstruir los axiomas sobre los que se ha sentado la subalternización de saberes ancestrales y populares, el proyecto intercultural tiene una especial y estrecha relación con algunos grupos académicos, algunos de ellos surgidos de o influenciados por la pedagogía crítica freiriana y, de manera más reciente, el programa modernidad/colonialidad.

De acuerdo con lo anterior, el traslape de lo étnico por lo cultural se debe al punto de vista o a la intención de las organizaciones y las comunidades étnicas y a la crisis de representación política del ocaso del siglo XX, como con las respuestas que esta suscitó en las personas-organizaciones no representadas y los académicos estudiosos o cercanos a ellas. Lo que expone esta parte del artículo son los apuntes obtenidos en el seminario de investigación sobre esa relación enunciada. Evidenciar las clausuras conceptuales producidas por el trabajo académico sobre las identidades y sus movilizaciones contribuye de manera superlativa a su debate y apertura.

El colapso del sistema soviético fue interpretado por los centros académicos ${ }^{8}$ como el triunfo del modelo de representación liberaldemocrático, además de la superación de cualquier antagonismo social basado en la ideología. El famoso fin de la historia anunciado por el apocalíptico Francis Fukuyama (1992), como se sabe, suponía

\footnotetext{
8 Me refiero a los lugares académicos que se suponen como enunciadores de ciencia/verdad, el escalón más alto de la jerarquía epistémica. Me valgo del trabajo de Restrepo (2012a) para situar estos centros en las metrópolis y en la periferia.
} 
Figura 1. Oxidente des-orientado

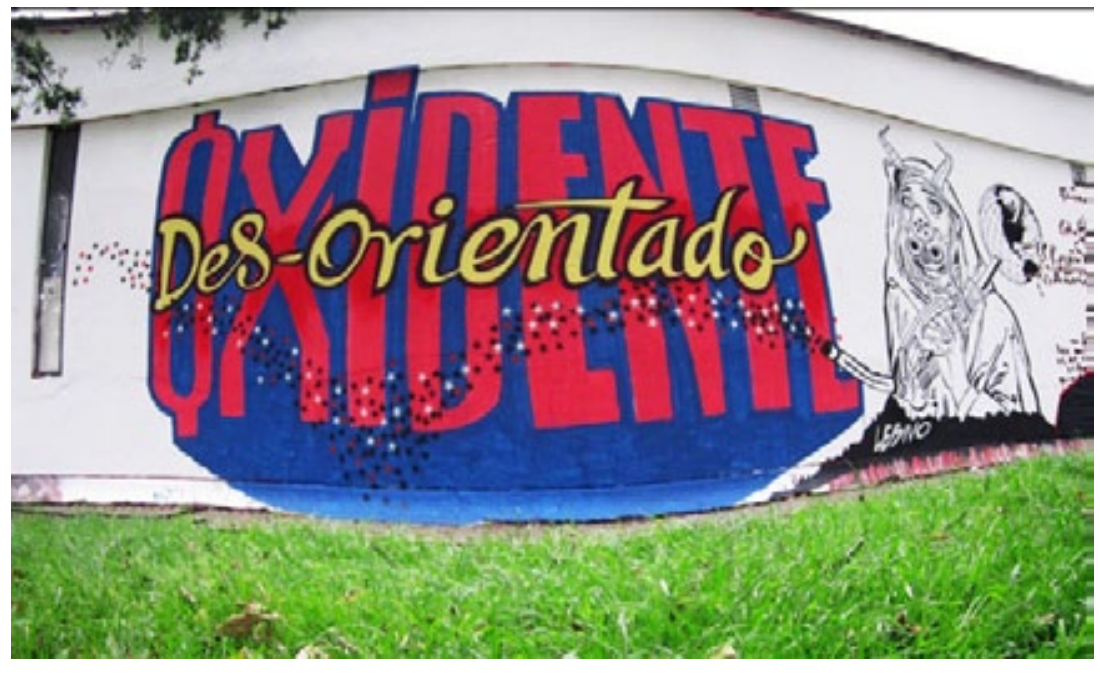

Fuente: Guache Street Art (2011).

la eliminación de cualquier antagonismo político (la pasión), ya que la economía de mercado — sin el tizón de la Unión Soviética- podría regular las relaciones entre los humanos en todo el planeta por medio de la razón y la jurisprudencia, como un consenso de adhesión a ciertos valores éticos y políticos. Esa característica general trazaba (y lo sigue haciendo) la diferencia entre lo normal/racional y lo extraño/pasional.

Sin embargo, en la misma década del noventa, el mundo vivenció la multiplicación de conflictos étnicos, de género, religiosos, gremiales, jidentitarios!, de grupos sociales que no encontraron sustento o lugar en ese consenso. La visibilización de estos excluidos no ocurrió por un reclamo nostálgico respecto a la alternativa del capitalismo que representaba la URSS, sino por una crítica tanto al marxismo y su reduccionismo de clases como al paradigma hegemónico y sus aspiraciones universalistas, lo que resultó aún más extraño.

Entonces, las luchas emprendidas por los excluidos del consenso mostraron esas contradicciones y tensiones entre: 
[...] sujeto y naturaleza; individuo y nación; identidad y fragmentación; economía y tecnología, y política y cultura. Conflictos que llevan a estos colectivos a imaginar y definir prácticas que apuesten por democracias más radicales, que trasciendan su nivel formal institucional e incluyan todas las relaciones sociales penetradas por el autoritarismo social y no solamente por la exclusión política en sentido estricto (Durán, 2008, p. 59).

En América Latina los ejemplos abundan: al siempre emblemático EZLN y sus redes de solidaridad activadas en todo el mundo podemos sumarle los piqueteros argentinos, ${ }^{9}$ la Asamblea Popular de los Pueblos de Oaxaca (APPO) ${ }^{10}$ y de manera más reciente el Colectivo Hip Hop Revolución de Venezuela ${ }^{11}$ y el Congreso de los Pueblos en Colombia. ${ }^{12}$ La emergencia de estos actores sociales significó el surgimiento de nuevos enfoques académicos, pues gran número de los "movimientólogos", como los llamó Fals Borda, coincidieron en que

9 Organización de acción directa conformada por movimientos de trabajadores y desempleados. Constituida en la década del noventa del siglo anterior, tiene profundas raíces en el movimiento anarquista de la Patagonia de las primeras décadas del mismo. Opera en diferentes frentes de acción, entre ellos uno de agitación y propaganda difundido por la banda de rock-fusión Las manos de Filippi.

10 Entre el 17 y el 21 de junio de 2006 se constituyó la Asamblea Popular de los Pueblos de Oaxaca (APPO), debido al fraude electoral cometido por el gobernador elegido Ulises Ruiz Ortiz (del partido PRI) y una serie de medidas en contra de la Sección 22 del Sindicato Nacional de Trabajadores de la Educación. La APPO reúne a más de trescientas organizaciones sociales de todo tipo (desde étnicas hasta contraculturales) y se ha caracterizado por su horizontalidad y la ocupación de varios centros de poder importantes, con el fin de subvertir las relaciones sociales establecidas. Llama la atención la redefinición de ciertas tradiciones y prácticas culturales como la Guelaguetza, una tradicional fiesta popular.

11 El HHR es un colectivo conformado por MCs (intérpretes de rap), grupos de rap y grafiteros, entre otras personas vinculadas al movimiento Hip hop de Venezuela. Tiene su punto de partida en el barrio 23 de enero, de Caracas, hacia 2002, como consecuencia del golpe de Estado contra el presidente Hugo Chávez. En sus inicios, la tarea recaía en la propaganda alternativa y popular del Gobierno bolivariano. En la actualidad participa en la Epatu (Escuela Popular de Arte Urbano) desde la base de que "el Hip Hop es una de las expresiones del poder creador del pueblo" (HHR, 2010).

12 "Proceso de carácter social y popular que convoca todas aquellas dinámicas y procesos de pueblos, sectores y regiones que estén dispuestas a emprender una construcción legislativa común para mandatar el futuro y el presente de nuestro país con una perspectiva latinoamericana y mundial" (Congreso de los Pueblos, 2013). 
los paradigmas empleados hasta entonces habían sido desbordados. No en vano, incluso desde la década del setenta del siglo anterior, las características particulares de esos movimientos locales - la problematización de sus identidades y necesidades en torno a las estructuras coloniales y la economía de mercado- significaron la proliferación de propuestas con acento local, como la Pedagogía Crítica, la Investigación Acción Participativa, la Teología de la Liberación y el Proyecto Intercultural.

A continuación, estableceré algunas características de los enfoques académicos dedicados al estudio de esas luchas sociales, con el fin de encontrar alguna causal respecto a aquello que he señalado como el traslape de lo étnico y lo cultural en el proyecto intercultural. No creo que esté siquiera cerca de ofrecer un mapa detallado de lo anterior; sin embargo, los apuntes extraídos de la experiencia del seminario conducen una línea argumentativa para el debate.

Como punto nodal de los NMS, Mauricio Pardo (1997) se refiere a una "crisis del proyecto de la modernidad" incitada por las fisuras sociales provocadas por el auge del neoliberalismo, la crisis de representación de los partidos políticos, el debilitamiento de las dictaduras militares y el agotamiento discursivo de los sindicatos y otras organizaciones de izquierda, sin olvidarnos de la represión de la que estas eran (y aún son) objeto (1997, p. 208). Para el autor, podemos situar en aquel entonces la germinación de los NMS, al menos para el caso de América Latina, con el logro de importantes reformas legales/institucionales incluso en materia de participación política. Mas la categoría de los NMS no debe llevarnos a entender que esas resistencias y resultados alcanzados (reconocimiento, visibilización, reforma) solo han sido posibles debido a una estricta organización de base. La presión social en diversos ámbitos y de diversas maneras también ha contribuido:

Para el final de los ochenta, la movilización de diferentes sectores sociales había logrado presionar la transición hacia regímenes civiles y la iniciación de reformas dirigidas hacia la "apertura del espacio político" en las administraciones sociales más antiguas. Aunque los partidos políticos de las clases dominantes se reaco- 
modaron después de unos pocos años, y no se prevé un cambio radical en el sistema político formal, ese considerable sector [...] ha logrado consolidarse (Pardo, 1997, p. 208).

Lo descrito no solo significa un cambio en las dinámicas hasta entonces habituales del ejercicio de la representación política; también dio un viraje en cuanto al vocabulario y los paradigmas políticos. Las anteriores "luchas contra el sistema", sustentadas en las estructuras de explotación y la dominación capitalista fueron reemplazadas por discursos que exigían la inclusión a ese mismo sistema por parte de los "sectores excluidos", pero con una particularidad: aquellas argumentaciones y las demandas que articulan se hicieron y se hacen hoy día en nombre de una identidad algunas veces "retocada" y otras "construida", con el fin de servir de capital a los sujetos de esas demandas (Segato, 2007, p. 15). ${ }^{13}$

Esta política de la identidad y los cambios discursivos a los que se refiere Segato, pueden ubicarse, al menos de cierta manera, en el caso colombiano. Hacia el amanecer de la década del noventa, una eclosión de organizaciones sociales basadas en la identidad se visibilizó en el espacio público y puso en jaque ciertas dinámicas consideradas habituales, así como los discursos académicos en los que se apeaban. Suele señalarse a la Constitución de 1991 como el punto nodal de esa eclosión; no obstante, la influencia que cierto sector de la academia colombiana marcado por la sociología francesa, bien vale la pena ser mencionada.

Veamos. Para algunos autores, entre ellos Tilly (1984) y Wallerstein (1990), la aparición de los movimientos sociales se remonta a la segunda década del siglo XIX. Como se intuye, tras dos siglos de existencia se ha llevado a cabo todo tipo de análisis respecto a las motivaciones

\footnotetext{
13 Un ejemplo específico, además de un caso muy interesante, es el que expone Édgar Ricardo Naranjo Peña (2012): "De la lucha por la tierra al reconocimiento de los derechos humanos: genealogía discursiva del Consejo Regional Indígena del Cauca". En este, el autor identifica "algunos procesos constitutivos y performativos del lenguaje que fueron determinando la identidad política de la primera organización indígena del país, el CRIC" (Rojas y Santamaría, 2012, p. xxix).
} 
de las personas y los grupos para organizarse y movilizarse. Aunque recientemente podemos hablar de los aportes de autores del denominado tercer mundo, la hegemonía en este campo ha estado mediada por los enfoques anglosajón y francés, como respuesta a los análisis psicosociales de la mitad del siglo XX. Autores como Turner y Killian (1957) y Smelser (1962), para nombrar algunos relevantes, de cierto modo continúan con las pistas trazadas por Le Bon ([1894] 1983), al sustentar la movilización social en estados emocionales colectivos como la rabia, la esperanza y la frustración. La respuesta anglosajona denominada "la escuela de la movilización de recursos" y de "estrategia" (Cohen, 1985), a grandes rasgos "se enfoca en cómo los grupos logran apropiar recursos económicos y organizativos, para dar curso por medio de la acción a los reclamos y reivindicaciones que están presentes de todas formas" (Pardo, 1997, p. 219). ${ }^{14}$ Por su parte, la sociología francesa - replicada en gran parte de Europa y cercana a la experiencia colombiana- estudia la movilización social, con acento "en la manera en que los grupos sociales se definen a sí mismos, activándose como sujetos políticos en contraste con las identidades salidas de la conceptualización hegemónica” (Pardo, 1997, p. 219). Esta última es la que ha puesto sobre la mesa el término de "nuevos movimientos sociales" y el núcleo de su propuesta es la identidad.

En Colombia, el estudio de las identidades de esos sujetos políticos como agentes frente a las nomenclaturas hegemónicas-coloniales se desplazó en especial a las comunidades étnicas. La participación relevante de organizaciones indígenas en el proceso constituyente de 1990 y 1991, así como la apertura de oportunidad política para las comunidades negras que significó el Artículo transitorio 55 de la Constitución (posterior Ley 70 de 1993), establecieron la ruta de lo que, con base en Eduardo Restrepo (2005), podríamos nombrar como una "etnización" de los estudios de la movilización social. ${ }^{15}$

14 Para una mayor precisión de estos enfoques y sus insumos en los estudios de movilización social en Colombia, el trabajo del profesor Freddy Cante $(2001 ; 2007 ; 2010)$ resulta bastante representativo.

15 La categoría de "etnización" trabajada por el antropólogo colombiano Eduardo Restrepo se refiere al "proceso mediante el cual una o varias poblaciones son imaginadas como una 
Tras una rápida revisión bibliográfica, es interesante dar cuenta de que antes de ese momento las publicaciones académicas o de organizaciones donde se apelara al capital étnico eran escasas. Entonces, la referencia a las formas de organización se hacía por medio de "movimientos cívicos", donde el significante "popular" tiene un rol central. Una característica de estos movimientos cívicos residía en la amplitud de sus componentes. Por ejemplo, como resultado de un taller nacional realizado en 1985 y en el que participaron organizaciones de todo el país, se plantea que estas "se inscriben dentro de una lucha por la democracia, en la cual hay que buscar la participación de los más amplios sectores" (Cinep, 1986, p. 102). Se alienta la característica "policlasista" de las organizaciones y se propone la alianza con "todos los sectores sociales excluidos". La alusión a grupos diferenciados étnicamente no constituye un pilar de acción. Caso similar ocurre con la Declaración política del encuentro de organizaciones sociales de Colombia, de 1989, donde se referencian los "sectores populares" como los sujetos de movilización (Organizaciones Participantes, 1995, p. 3).

No debe entenderse que hasta entrada la década del noventa del siglo anterior no existiera una movilización de tipo étnico, pues eso sería una tremenda imprecisión. ${ }^{16}$ Vale la pena insistir en que me refiero al lenguaje político y académico y a su desplazamiento en épocas más recientes hacia la identidad etnizada. Esto no debe asumirse con gradación positiva o negativa; más bien, lo que me interesa resaltar es que, en dos momentos históricos encarnados en los discursos de las organizaciones sociales, existe una identificación (más amplia, en un caso y en otro, más específica) del sujeto que constituye y enuncia ese discurso. Comprendo las prácticas interculturales como la posibilidad

comunidad étnica". Advierte que es un proceso continuo y conflictivo que "incluye la configuración de un campo discursivo y de visibilidades desde el cual se constituye el sujeto de la etnicidad” (Restrepo, 2005, p. 143). Me sirvo de esa categoría para nombrar, someramente, la producción académica en torno a la diferencia cultural/étnica en la década del noventa.

16 Su poca referencia bibliográfica no supone una ausencia real de las organizaciones sociales étnicas en aquel entonces. Édgar Ricardo Naranjo (2012) ofrece un par de lecturas detalladas respecto a la historicidad del movimiento indígena del Cauca y la Confederación Indígena Tayrona. 
de apostar por la equivalencia tanto de estos sujetos, como de otros que ni siquiera son objeto de estudio.

Además de la visibilización en el espacio público nacional, el "capital étnico" de los movimientos sociales (Santamaría, 2008; 2013) ha permitido la creación de alianzas y redes internacionales que han contribuido al fortalecimiento de las estrategias y los repertorios de las organizaciones. El caso de las zonas humanitarias y de biodiversidad en el Bajo Atrato colombiano es bastante representativo. En su trabajo de grado, la internacionalista Lorena Romero Ramírez (2013) da cuenta de la manera en que la conformación de unas redes transnacionales de defensa - lo cual apelan a su condición de afrocolombianos y todo lo que ello representa en el ámbito político y jurídico- desde las comunidades de Curvaradó y Jiguamiandó, víctimas de desplazamiento forzado en 1997, ${ }^{17}$ contribuyó al conocimiento internacional del caso y activó diversas campañas de organizaciones defensoras de derechos humanos en varios lugares del planeta. Lo que Keck y Sikkink han llamado "modelo de búmeran" (2000) ha contribuido en las estrategias de presión social que obliteran los bloqueos legales, políticos e institucionales que suelen afectar los repertorios de acción de las organizaciones sociales, en particular las étnicas. Es lo que desde Stefano Varese (1996) ha sido conocido como "la globalización desde abajo”, es decir, la oportunidad de que los pueblos oprimidos históricamente por los Estados-Nación visibilicen sus identidades en el orden mundial, al fragmentar la rigidez de las fronteras nacionales y oponer resistencia directa a las presiones de los Estados y las corporaciones de capital transnacional.

Aunque existen aportes e influencias de algunos autores metropolitanos respecto a la acción colectiva en América Latina, también hay

\footnotetext{
17 El 26 de febrero de ese año, la Brigada 17 del Ejército colombiano, comandada por el entonces general Rito Alejo del Río, ejecutó una operación militar en connivencia con grupos paramilitares, lo que causó el desplazamiento forzado de más de 4.000 campesinos mestizos y afrodescendientes de los territorios colectivos obtenidos mediante la Ley 70 de 1993. Varias empresas palmicultoras ocuparon de manera ilegal esos territorios y afianzaron el poder paramilitar en la zona por medio de persecuciones, amenazas y dislocación del tejido comunitario (Romero, 2013).
} 
quienes tienen una postura crítica, sobre todo en torno a la categoría de NMS. Para un amplio sector de la sociología francesa, la movilización social en Europa había sido la respuesta a la "crisis de la modernidad", por lo que resultaba una contradicción bautizar así a las organizaciones latinoamericanas, residentes de una región donde la modernidad "no ha terminado de llegar" (Flórez-Flórez, 2007, p. 246). Desde la literatura especializada y con un énfasis decolonial, Juliana Flórez-Flórez recrea esas críticas. Touraine afirma que esas organizaciones deben considerarse como “"movimientos socio-históricos', en el sentido de que suscitan procesos de cambio histórico y de desarrollo, orientados hacia la obtención de una mayor participación en el sistema político" (2007, p. 246). Con argumentos similares, otros autores han propuesto el apelativo de "movimientos populares" (Foweraker), "culturales" (Khosrokhavar) o "viejas luchas" (Mainwarning y Viola).

Esta cooptación de la categoría NMS muestra un claro sesgo eurocéntrico en el estudio de las identidades y sus movilizaciones. Es, por demás, el desafío epistemológico descrito por Durán líneas atrás. Al parecer, la complejidad de las luchas subalternas de América Latina enmarcadas en la crisis de representación política, la radicalización de la economía capitalista, la exclusión de las comunidades étnicas, la violencia estructural, los conflictos armados, el desplazamiento forzado, el machismo/patriarcado y la explotación indiscriminada del medio ambiente no fue asumida de forma integral (con afortunadas excepciones) por los académicos del primer mundo. Sin embargo, la respuesta de un buen número de autores latinoamericanos y latinoamericanistas con una estrecha relación con las organizaciones sociales no se hizo esperar: el Programa Modernidad/Colonialidad ${ }^{18}$ y el Proyecto Antropologías del Mundo, ${ }^{19}$ entre tantos otros, dan buena cuenta de ello. La proliferación de publicaciones académicas y cátedras así como grupos y proyectos de investigación en torno a las reivindicaciones de carácter étnico son un resultado de esa respuesta.

\footnotetext{
18 Para mayor detalle, puede verse Escobar (2003).

19 Para mayor detalle, puede verse Restrepo (2012).
} 
Otra consecuencia podría ser una suerte de retorno al territorio, es decir, el encuadre del lente en las acciones "en zonas periféricas concretas", debido a que el protagonismo de los estudios había sido desplazado hacia una respuesta a la globalización, las redes transnacionales, la diplomacia desde abajo y los escenarios internacionales de defensa de los derechos humanos (Flórez-Flórez, 2007, p. 247). Esto no quiere decir que los autores de la periferia se quedaran absortos observando su propio ombligo; el trabajo ha sido juicioso en el doble sentido de lo local y lo global. Un ejemplo preciso de ello es la obra de Arturo Escobar (1997; 2005; 2012), Escobar y Pedrosa (1996), César Rodríguez Garavito y García Villegas (2005); y Rodíguez Garavito y De Sousa Santos (2003) y la ya referenciada de Ángela Santamaría (2008; 2009), como ejemplos desde tres enfoques diferentes.

Tanto la proliferación académica de estudios localizados como la aparición de organizaciones sociales de este tipo no deben verse como positivas en sí mismas. Por ejemplo, para Christian Gros en el caso colombiano es difícil afirmar que las comunidades organizadas hayan ganado autonomía frente al Estado; al contrario, muchas reformas en materia de inclusión han sido impulsadas desde las instituciones. Esto muestra:

progresivamente la idea de que el Estado podría sacar ventajas de "administrar la etnicidad" en vez de trabajar por su desaparición $[\ldots]$ al punto de que en la actualidad es incuestionable que se pueden encontrar fácilmente casos en que una organización indígena deba su existencia, más a la voluntad interesada del Estado que a una lucha emprendida por la base para hacer reconocer su presencia, defender su autonomía y asegurar el logro de sus reivindicaciones (Gros, 1997, citado en Segato, 2007, p. 39).

Una afirmación similar hace el líder del Movimiento Nacional Cimarrón Juan de Dios Mosquera respecto de la Ley 70 y la conformación de Consejos Comunitarios de las comunidades negras:

Muchos se organizaron pero para constituir Consejos de papel $[\ldots]$ a veces pareciera que lo que hizo fue parcelar, fragmentar a 
los afrodescendientes, mantenerlos en ciertos lugares impidiendo que se desarrollara el proceso que se llevaba a cabo por los noventa (J. de D. Mosquera, comunicación personal, 8 de marzo de 2012).

En Colombia, la emergencia de las comunidades étnicas como sujetos políticos y su relación cercana con académicos influenciados por la teoría de la movilización social — que pone el acento de sus propuestas en la constitución de identidades contrahegemónicas - significó una especie de efecto dominó que ha posicionado a las organizaciones sociales étnicas en el centro del debate académico. Si bien esto ha contribuido a la visibilización de sus conocimientos, demandas y proyectos, en el caso del discurso intercultural también ha significado que este se enquiste en la participación de comunidades de ese tipo y ha olvidado que el espectro de cultura se relaciona con el componente étnico, pero no se supedita a él. El proyecto intercultural propone la desactivación de los dispositivos coloniales instalados en los más diversos campos de la sociedad colombiana que han servido como artefacto de subalternización para esas comunidades y también para otros grupos sociales: las mujeres, los campesinos, las minorías religiosas y las culturas sub. Lejos de haber superado los antagonismos, las dinámicas de la democracia liberal y el capitalismo tardío han endurecido y sofisticado las jerarquizaciones y exclusiones (las políticas con enfoque diferencial son muestra de ello). Aún hoy, más de veinte años después de la Constitución de 1991, de la Ley 70 de 1993 y de un cuerpo jurídico robusto que pretende la inclusión y salvaguarda de los sujetos subalternados, las dinámicas que las sustentan siguen marchando; es lo que Rodríguez Garavito ha llamado "la paradoja fundamental del derecho en Colombia” (2009, p. 18).

El epígrafe con el que empezaba esta parte del artículo es parte de la letra de la canción "Korsakov" del grupo de punk español Boikot. Se refiere a las paradojas que suscitó la caída del muro de Berlín. "Y ahora todos juntos como hermanos" habla de ese consenso que garantiza la supuesta superación de los antagonismos sociales y la idea de inclusión por medio de reformas - algo parecido al "mundo donde todos los estilos de vida tienen lugar" descrito por Zizek-, mientras la segunda parte "vamos de la mano a comer a un Burguer King" completa 
la sentencia, pues está claro quién sirve el menú, qué tipo de menú se sirve y cómo se debe comer.

\title{
"Ahora la cultura explica todo"20
}

\author{
...un nuevo orden \\ revolución mental \\ un nuevo orden \\ deconstrucción cultural. \\ Ultrágeno (2002, pista 12).
}

Como lo señala Axel Rojas (2011), "sobre la cultura recae hoy en día una atención inusual, que se expresa tanto en las formas más aceptadas y extendidas de pensar el momento histórico como las características de muchas de sus disputas" (p. 174). La cultura aparece en el mundo de hoy como un capital tanto en el ámbito privado como en el público. Por un lado, sirve como argumento para blindar los estilos de vida más particulares e individuales y, por el otro, ha servido como garante de la visibilización y la lucha por los derechos de grupos étnicos subalternados. No podemos olvidarnos de que la cultura también ha servido como argumento para la superioridad y para esa misma subalternización. No tenemos que ir muy atrás en la historia para hablar de los sendos procesos de colonización y del mantenimiento de las relaciones de poder establecidas por este y reforzadas por el Estado-Nación; el traslape entre lo étnico y lo cultural que he señalado, es también un capital, no para la reafirmación de particularismos o para la lucha de las organizaciones sociales, sino para cometer todo tipo de horrores. ${ }^{21}$

No obstante, la indeterminación del significado no debe verse como algo negativo. Al contrario, el trasegar de la cultura por diversos

\footnotetext{
20 Afirmación de Michel-Rolph Trouillot (2011, p. 176).

21 Un ejemplo es el caso del periodista británico Robert Fisk (citado en Segato, 2007), acerca del despojo de los musulmanes bosnios por los serbios: “iLimpieza étnica!, qué fácilmente nosotros los reporteros aceptamos esta frase cuando los musulmanes estaban viviendo en hogares devastados y estaban siendo violados y asesinados por los serbios, no porque eran étnicamente diferentes de sus agresores serbios, sino porque los serbios querían las tierras de los musulmanes, y las tomaron" (p. 16). Lo interesante de este caso es ver cómo la cultura/etnia se convierte en la categoría que explica un tremendo y desigual enfrentamiento y distrae la atención de la raíz del asunto: la tierra y, claro, su utilización.
} 
discursos y con intenciones diferentes puede contribuir no solo para mostrar su importancia, puesto que la evidencia como una construcción social, mutable, porosa, difícil de clausurar, que no es ajena ni independiente del tiempo y del espacio. Esa es parte fundamental de mi argumento sobre la necesidad de apertura del proyecto intercultural: el acto dialógico que esto supone es un ejercicio de doble vía de construcciones sociales, de maneras de interpretar y resolver el mundo. Es un quilt de discursos.

No quiero desviar la conversación, pero antes de abordar el tema puntual del proyecto intercultural me parece oportuno señalar algunas pistas sobre lo que en el Seminario de investigación hemos construido acerca de la aparición de "la cultura" como capital. Es pertinente la genealogía realizada por Gustavo Bueno (1992), quien señala que para las ciencias sociales:

[...] el concepto de "cultura" resulta central a la manera como el concepto de "energía" es uno de los conceptos centrales de la física. Pero mientras el segundo ha alcanzado una definición operacional (por medio del concepto de trabajo) en la que los físicos pertenecientes a las escuelas más diversas están de acuerdo, en cambio puede afirmarse que cada escuela de antropólogos ofrece un concepto de "cultura" diferente.

De igual manera ocurre en el caso de las organizaciones sociales étnicas en Colombia, donde se crean fuertes tensiones respecto a la legitimidad cultural entre comunidades y Pueblos. ${ }^{22}$ Bueno sitúa la amplitud de la categoría de cultura en la definición que E. B. Tylor ${ }^{23}$ ofreció y la apa-

\footnotetext{
22 Durante un trabajo de observación realizado en diferentes encuentros entre organizaciones indígenas de Colombia (encuentros regionales, mesas de concertación y congresos nacionales) entre 2009 y 2013, pude captar esas tensiones. Me llamó la atención la posición de algunas miradas más tradicionalistas sobre procesos de resignificación cultural recientes como el del pueblo kankuamo, el pueblo muisca o las comunidades negras. Se consideran, en esos casos, como ilegítimas o artificiales.

23 Recordemos que para Tylor (1871) cultura es sinónimo de civilización, "en sentido etnográfico amplio, es aquel todo complejo que incluye el conocimiento, las creencias, el arte, la tecnología, la moral, el derecho, las costumbres y cualesquiera otros hábitos y capacidades
} 
rente facilidad que ha mostrado en mantenerse hasta nuestros días (con todos sus tira y afloje). Esta definición, que Bueno llama "denotativa", es un todo complejo que permite que las relaciones sociales entre los miembros de una comunidad (y los productos que resultan de ello) sean llamados cultura y que alguien que lee y conoce de artes sea considerado culto. Sin embargo, aunque amplia, esta definición también segrega: en tanto que abarca "todo aquello que no es naturaleza", se opone a ella.

En esta segregación, hemos identificado en el Seminario, puede residir un argumento histórico (además de todos los señalados, por ejemplo, por la abundante bibliografía de los autores de la inflexión decolonial) de la subalternización de las culturas asumidas como ancestrales, diferenciadas. La relación estrecha entre la naturaleza y el mito fundacional de los Pueblos indígenas es menospreciada por esta idea de cultura/ civilización, centrada en la idea evolucionista, esto es, la concepción del tiempo lineal característica del pensamiento eurocentrado y ajena a los Pueblos, que además los ubica en un momento anterior (más cerca de la incivilidad primigenia) e inserta violentamente los discursos del "progreso" y el "desarrollo" con el ánimo de "civilizar", de trazar la frontera entre el reino de la naturaleza y la cultura humana, es decir, el dominio y el usufructo que entiende la naturaleza como meros recursos.

Esa manera de anteponer una cultura y considerarla superior a otra tiene una obvia consecuencia: la subalternización de conocimientos. Mientras las culturas/civilizaciones adelantadas se suponen como enunciadoras de verdad, de ciencia (transformación y control de lo natural), los saberes diferenciados, no hegemónicos, son mero folclorismo, apenas una ontología naturalista digna de ser valorada. Como se sabe, Castro-Gómez (2007) insiste en que esa mirada particular — que él llama "colonial" - sobre el mundo "obedece a un modelo epistémico desplegado por la modernidad occidental" que denomina "la hybris del punto cero" y que podríamos definir como "la pretensión de Occidente de hacerse un punto vista sobre todos los demás [...],

adquiridos por el hombre en cuanto a miembro de la sociedad" (citado en Minchinela, 2012, p. 152). 
pero sin que de ese punto de vista pueda tenerse un punto de vista" (Castro-Gómez, 2007, p. 83).

Por esto, diversos autores como el mismo Castro-Gómez, Walter Mingolo o la ya citada Walsh han propuesto que la primera puntada para hilvanar un proyecto de sociedad alternativo al actual hegemónico (racista, sexista, patriarcal, capitalista y violento con la naturaleza) es la recuperación de los saberes subalternizados y hacer visibles "los otros puntos de vista". Mas esos puntos de vista y sus luchas deben apostar por mantener su diferencia no solo como derecho, sino como alternativa política:

[...] la lucha de los movimientos sociales inspirados en el proyecto de una "política de la identidad" no alcanzará la radicalidad del pluralismo que pretende afirmar a menos que los grupos insurgentes partan de una conciencia clara de la profundidad de su "diferencia", es decir, de la propuesta de mundo alternativa que guía su insurgencia [...]. Afirmar la diferencia de las culturas en un sentido denso es afirmar la posibilidad de que otros valores y otros fines orienten la convivencia humana (Segato, 2007, p. 18).

Esta diferencia entre los saberes legítimos y los folclóricos, entre la cultura hegemónica y las diferenciadas, tiene cierta intersección con la diferencia establecida por parte de algunos autores de la ciencia política en cuanto a lo político y la política. El primero reconoce el carácter antagónico de la vida en comunidad, o sea, las relaciones de identificación a partir de la diferencia, mientras la política "consiste siempre en 'domesticar' la hostilidad y en tratar de neutralizar el antagonismo potencial que acompaña toda construcción de identidades colectivas" (Mouffe, 1999, p. 14). Si bien la mirada hegemónica del mundo reconoce a las otras culturas, existe siempre una intención de domesticarlas, neutralizarlas y mantenerlas como saberes menores. Por ello será que desde lo institucional se hace tanto énfasis en el lenguaje de lo políticamente correcto, donde la diferenciación es sinónimo de subalternidad: minorías, folclor, herencia, inclusión, política diferencial, ley de cuotas son apenas algunas muestras de ello. En palabras de Juan de Dios Mosquera, “aún hoy, más de 150 años luego de la 
Figura 2. "El poder de uno"

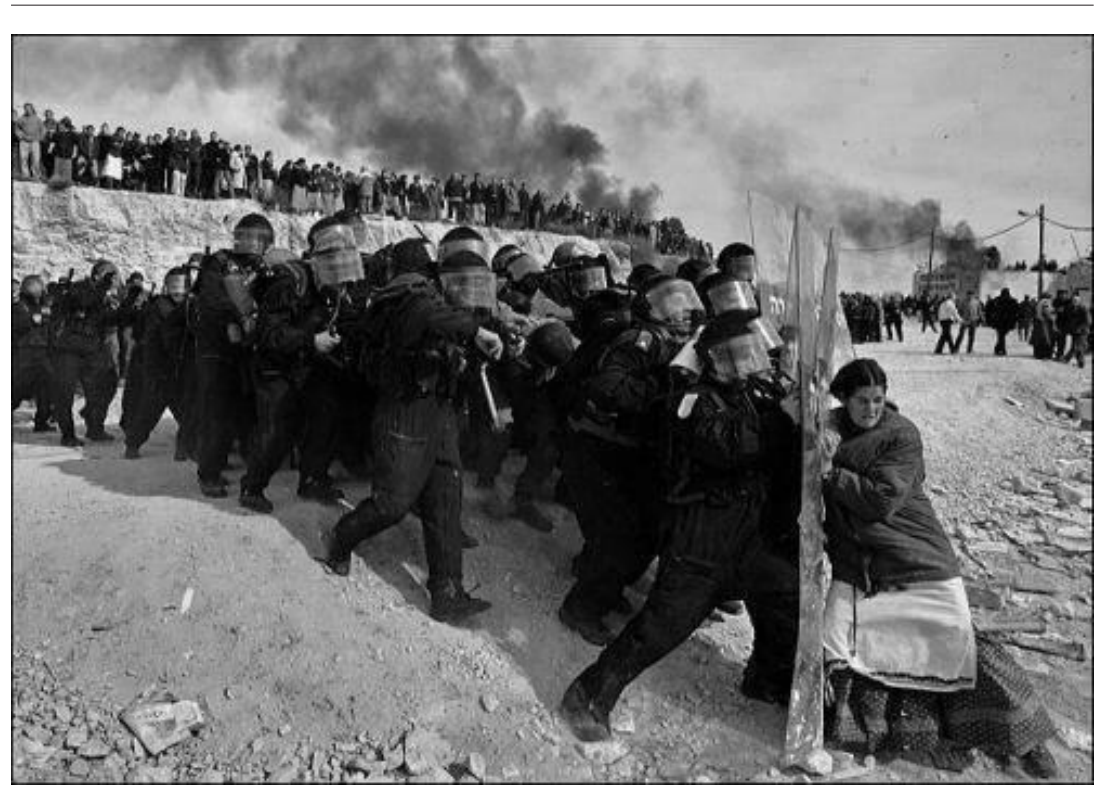

Fuente: Oded Balitti (2007).

Fotografía ganadora del Premio Pullitzer en 2007. Mujer en oposición a las fuerzas de Policía en la ribera occidental del río Jordán. http:/ /www.taringa.net/posts/imagenes/15300610/19-Fotosque-obtuvieron-el-premio-Pulitzer.html

abolición de la institución de la esclavitud, hablamos de inclusión ¿Qué significa eso? Pues que estamos fuera, que no existimos" (J. de D. Mosquera, comunicación personal, 8 de marzo de 2012). Por otro lado, lo político tiene una mayor relación con la idea del proyecto de interculturalidad, en tanto parte del reconocimiento de la diferencia/ antagonismo y propone un diálogo entre esas diferencias, no como mera administración o herramienta para neutralizar, sino como posibilidad de construcción.

Catherine Walsh (2007) propone una diferencia entre dos concepciones de interculturalidad. Según la autora, el empleo del significante ha sido tal, que incluso el Ministerio de Educación colombiano ha hecho (ab)uso de este, al igual que algunos organismos internacionales como el BID, el Banco Mundial o la Unesco (¿la política?). Existe una significación "contrahegemónica" de la interculturalidad que tiene como 
objetivo "enfrentar los legados coloniales, incluyendo las geopolíticas del conocimiento" (¿lo político?) (Walsh, 2007, p. 32).

Con respecto a ese objetivo, un caso interesante puede ser el de la etnización y la organización de las comunidades negras del Bajo Atrato. Con esto no quiero bautizarlo como un hito de interculturalidad, mas he identificado unas características que se refieren a la posibilidad de articulación de identidades étnicas con otras identidades, la deconstrucción de prácticas y lenguajes racistas y el enfrentamiento a los legados coloniales. Eduardo Restrepo (2005; 2011) ha mostrado cómo los procesos de organización social de la década del ochenta del siglo anterior en esa parte del Chocó tuvieron una influencia de académicos interesados en la zona (colombianos y extranjeros), activistas (colombianos y extranjeros), campesinos (negros y mestizos), misioneros claretianos (colombianos y extranjeros) e incluso algunos funcionarios del Estado. Con todas las críticas que pueden avivar esos hechos históricos y lejos de su idealización, la literatura sobre ese proceso y el diálogo con algunos de sus protagonistas muestran un ejercicio basado en el aprendizaje mutuo y la solidaridad. En una entrevista realizada por mí a uno de los acompañantes permanentes en las zonas humanitarias de Curvaradó y Jiguamiandó abordamos el tema de la constitución de una identidad comunitaria; resultó que algunos de los discursos, los repertorios y las estrategias de acción de las comunidades habían surgido de las experiencias compartidas con otros grupos sociales organizados, como las acciones jurídicas de los afroamericanos en los Estados Unidos, las propuestas autonómicas de los zapatistas en México, la propuesta de neutralidad activa de la Organización Indígena de Antioquia o los métodos piqueteros en Argentina. Vale la pena poner sobre la mesa la discusión constante que los miembros de la Asociación de Consejos Comunitarios y Organizaciones del Bajo Atrato (Ascoba) han tenido acerca de la categoría de "comunidad negra" establecida por la Ley 70 de 1993. La activa participación de personas mestizas en los procesos organizativos y los lazos de solidaridad construidos durante décadas problematizan y desbordan una noción de cultura meramente étnica (Ascoba, 2010). Otros ejemplos interesantes de constante ejercicio dialógico entre identidades diferenciadas, pueden ser el tejido de comunicaciones de la Asociación de Cabildos Indígenas del Norte del 
Cauca (ACIN) ${ }^{24}$ o la manera en que la exconcejala por Bogotá y lideresa indígena arhuaca Ati Quigua ha construido una plataforma política con la participación de diversos procesos identitarios (Rodríguez, Rojas y Santamaría, 2012).

El diálogo constante entre culturas no es la meta lograda; por eso mismo, en estas páginas, en la obra de los autores citados y en las comunicaciones con las organizaciones y sus líderes se habla de la interculturalidad como proyecto, desde luego, que aún no se ha alcanzado. El diálogo y el intercambio - la articulación — son puntos de partida fundamentales, pero las raíces de la "mirada colonial del mundo" son tan profundas en nuestras sociedades que el trabajo es mucho más arduo, "apuntala y requiere la transformación de las estructuras, instituciones y relaciones sociales, y la construcción de condiciones de estar, ser, pensar, conocer, aprender, sentir y vivir distintas" (Walsh, 2010, p. 78).

El proyecto, además, tiene sus matices y características que varían (en algunos casos más, en otros menos) dependiendo de las organizaciones y sus interpretaciones sobre qué es la cultura y qué están dispuestos a aprehender de los otros. Todo esto suena utópico, es cierto. Imaginarnos un mundo con relaciones sociales más equitativas resulta esperanzador, pero su construcción y materialización resulta problemática. El capitalismo funciona hoy día como lo ha hecho la religión por muchos años. Hace unos siglos, para el catolicismo era absurdo pensar en una sociedad que no sustentara todas sus acciones en el hecho religioso; la pira así lo demostró. Mas un proceso histórico (en el que la categoría de cultura, al entender de Gustavo Bueno, tiene mucho que ver) de largo aliento donde la contingencia de otras maneras de resolver el mundo sirvieron de barricada al fundamentalismo religioso resultó en el imposible: sociedades ligadas a la religión por tradición, pero que constituyen Estados e instituciones laicas y defienden y alientan la diversidad de credo (al menos en el discurso público). Hoy nos cuesta apostarle a un mundo donde otras maneras de administrar los recursos y las personas sean más humanas; ya no

24 Para mayor detalle, puede consultarse: http://videocomunidad.univalle.edu.co/descargas/Tejido_de_comunicacion.pdf 
existe la pira, pero las "guerras contra el terrorismo", la injerencia diplomática, los planes quinquenales, las luchas antisubversivas, las Procuradurías, etc., están alertas. No podemos partir de la idea de que el proyecto intercultural —una sociedad alternativa — se hace de un día para otro, con el voto a tal o la reforma aquella.

Desde los sectores académicos cercanos los movimientos sociales se hacen críticas despiadadas sobre cualquier proyecto alternativo de sociedad. Es como si existiera una fórmula específica, unos polvos mágicos para aplicar aquí y allá y que por arte de magia —o de ciencia - resultará en una postal de paz. Al menos en Colombia no podemos decir que, luego de doscientos años de Estado y de ser uno de los países en la región con mayor tradición democrática (elecciones libres y continuas, instituciones independientes, etc.) tengamos hoy una sociedad realmente democrática, un Estado de Derecho consolidado, etc. Los “proyectos insurgentes" tampoco se consolidarán de un día para otro, mucho menos cuando al mismo Estado y al sistema económico le resultan tan incómodos.

El proyecto intercultural como alianza entre saberes y puntos de vista subalternizados tiene como principal tarea inscribir en la historia nacional y universal lo que en la Historia, con mayúscula, ha sido borrado. Para ello, es fundamental el carácter radical de la diferencia, la complicidad entre identidades congeladas por una política globalizada afín al capitalismo, por un lado y, por el otro, el universalismo inherente al Estado moderno, que impide que las tramas históricas particulares urdan creativamente el tiempo heterogéneo del planeta y, en especial, del país (Segato, 2007, p. 21).

Aquí es donde el estudio de los nuevos movimientos sociales empieza a tener mayor sentido. Más allá de la teorización, la esquematización y la bendición que suele darles, el campo académico desempeña un papel principal en la medida en que la inscripción de esas historias locales, esos territorios, esos damnés de la terre, sus luchas, sus resistencias, su creatividad, sus construcciones y sus aportes deben encarar los más diversos frentes y hacer de los sujetos que representan, interlocutores reales. El académico es un campo en constante batalla. 
Dos de las ideas que he expresado desde el preludio de estas páginas, han sido, primero, la relevancia de un estudio juicioso de los movimientos sociales contemporáneos para contribuir a una discusión que, desde diferentes enfoques y geografías, ha intentado leer el problema de las identidades y la representación política/cultural. Un poco más al respecto: la necesidad de hacer ese estudio que transgrede las fronteras disciplinarias, en particular, los clichés de lo que es o no un NMS, de lo que es o no una identidad legítima, pero sobre todo, pone el acento en la diferencia radical entre los proyectos políticos alternativos de las organizaciones sociales y el binomio Estado modernocapitalismo. Esta primera idea queda sobre la mesa con la propuesta de que esa diferencia radical y esos proyectos políticos solo pueden insertarse en el espacio público nacional e internacional por medio de un quilt discursivo, al que, de acuerdo con algunos autores, he llamado "proyecto intercultural". La segunda idea es que para que aquel proyecto continúe manteniendo la diferencia radical como elemento constitutivo, la interculturalidad debe evitar su clausura provocada por el traslape cultura/etnia e invitar a "otros puntos de vista" — para recordar a Gómez-Castro- a que inscriban sus historias particulares y a que formen parte del diálogo (la articulación). La propuesta radica en el aporte que los movimientos contraculturales, mediante sus versiones del mundo, pueden hacer en la deconstrucción de las prácticas sociales hegemónicas y la construcción de modelos alternativos de representación.

\title{
Orden público alterado: algo se mueve bajo el suelo
}

\author{
[...] Como ellos, me aburrí viendo desfilar hediondos profesores y \\ bandas de guerra mientras al fondo soltaban feroces escupitajos y \\ pedos entrecortados. Entonces salté por la ventana y pisé el acelerador \\ a fondo, entré en contacto con el pasto y las libélulas, y luego ya no \\ bubo pasto sino un tictac prometedor, un brusco amago de música y \\ otros que como yo buscaban la comba al palo. \\ Medina Reyes (2003, p. 12)
}

Una de las últimas sesiones semestrales del Seminario de investigación tiene como tema principal el de la contracultura. Hace un par de semestres, recuerdo, uno de los estudiantes manifestó su malestar 
porque, según él, abordar el tema de la contracultura luego de abordar la causa indígena, el movimiento afrocolombiano, el de diversidad sexual y el de mujeres significaba "meter en la misma talega a indígenas, afrodescendientes, mujeres, punkeros, transexuales, etc.". Su indignación radicaba en una cierta jerarquización de las identidades que abordábamos en las sesiones de la clase. Para él, las identidades étnicas estaban en la parte más alta, las sexuales o de género eran una especie de clase media y el resto apenas constituían el lumpen de esa escala. De cierta manera, parece estar en lo cierto. Cuesta mucho imaginarse una política diferencial hacia un grupo de personas que se identifique con la música rap o la estética metalera. Cuesta tomar en serio estos grupos de personas, "meterlos en la misma talega" si en sus discursos no hay argumentos ancestrales, no son objeto directo de violencia estructural, no son blanco de grupos armados al margen de la ley, no forman parte de alianzas ni se constituyen como grupos de presión. Parte de mi interlocución con Andrés, ese era su nombre, fue hacerle ver que al "meterlos en la misma talega" no estábamos diciendo que fueran iguales, tampoco mejores los unos o peores los otros; que intentábamos señalar cómo aquella crisis de la modernidad, del Estado-Nación o del sistema capitalista (que consideramos como punto nodal de los NMS y a las que me he referido con anterioridad) no solo había activado las políticas de identidad de las comunidades étnicas, de las mujeres, de los grupos religiosos, el ambientalismo o lo trans, sino que había ciertos procesos de representación política y cultural que se configuraban a partir de interpretar y resolver el mundo desde la música, el cómic, el grafiti, el barrismo, determinado tipo de estética urbana y discursos que no recurrían —al menos de forma habitual - a capitales raciales, étnicos, ancestrales, espirituales, sexuales y que, además, no necesariamente debían ser antagónicas.

Aquella explicación ofrecida a Andrés, al igual que las líneas que aparecen en esta suerte de introducción a la tercera parte del artículo, son un asunto sensible. $D$ 'habitué el tema de la contracultura es percibido como poca cosa, sin importancia concreta. En muchos casos, esto de poner sobre la mesa a los movimientos contraculturales y plantear un diálogo con otros movimientos o agremiaciones "serias" no es visto con muy buenos ojos. Hoy día la contracultura se reduce a lo que los 
medios masivos y algunos académicos en su afán de nombrarlo todo han denominado "tribus urbanas". Crestas de colores, pelos largos, camisetas negras con el nombre de alguna banda, pantalones rotos, botas, taches, ropa ancha, gorras, tatuajes, perforaciones y, claro, drogas, ruido, desenfreno, alcohol, sexualidad a flor de piel... Quienes han adoptado una manera de ver e interpretar el mundo por medio de cierta música, de cierta estética y de cierto lenguaje muestran con orgullo una diferencia que se manifiesta en esas cosas. Lo que me parece interesante es ver de dónde surgen y qué pretenden esos procesos transgresores de significación/representación. ¿’Por qué recurrir a estos procesos de significación en sociedades democráticas donde existe un supuesto amplio abanico de posibilidades de representación? ¿Por qué resultan transgresores, si el sustento de esas sociedades democráticas (o al menos de eso han intentado convencernos) es la libertad de expresión?

Para Guillem Martínez: "En un sistema democrático, los límites a la libertad de expresión no son las leyes. Son los límites culturales. Es la cultura" (Martínez, 2012, p. 14). Poco importa un quebrantamiento de la ley, siempre y cuando se haga dentro de esos límites culturales, al igual que de poco sirve la ley si apunta a subvertir, ampliar o replantear esos cánones.

El tema del grafiti resulta ilustrativo. En una investigación desarrollada para el Seminario en el segundo semestre de 2012, una estudiante planteó el estudio de la eclosión del grafiti en Bogotá. Si bien las paredes de la ciudad suelen estar pintadas, desde hace unos diez años llaman la atención los colectivos y artistas urbanos que, en gran número y diversos estilos, han irrumpido en el distrito capital. ${ }^{25} \mathrm{Ha}$ sido tal el movimiento, que en 2011 el Gobierno de la ciudad expidió un Proyecto de Acuerdo "Por medio del cual se regula la elaboración de grafitis en el Distrito Capital" y los destacó a manera de manifestacio-

25 Ejemplo interesante resulta el trabajo a varias manos realizado por Toxicómano, Lesivo, DJLU y Guache, conocido como Bogotá Street Art. Para mayor información, puede verse: http://www.bogotastreetart.com/index2.htm 
Figura 3. Grafiti

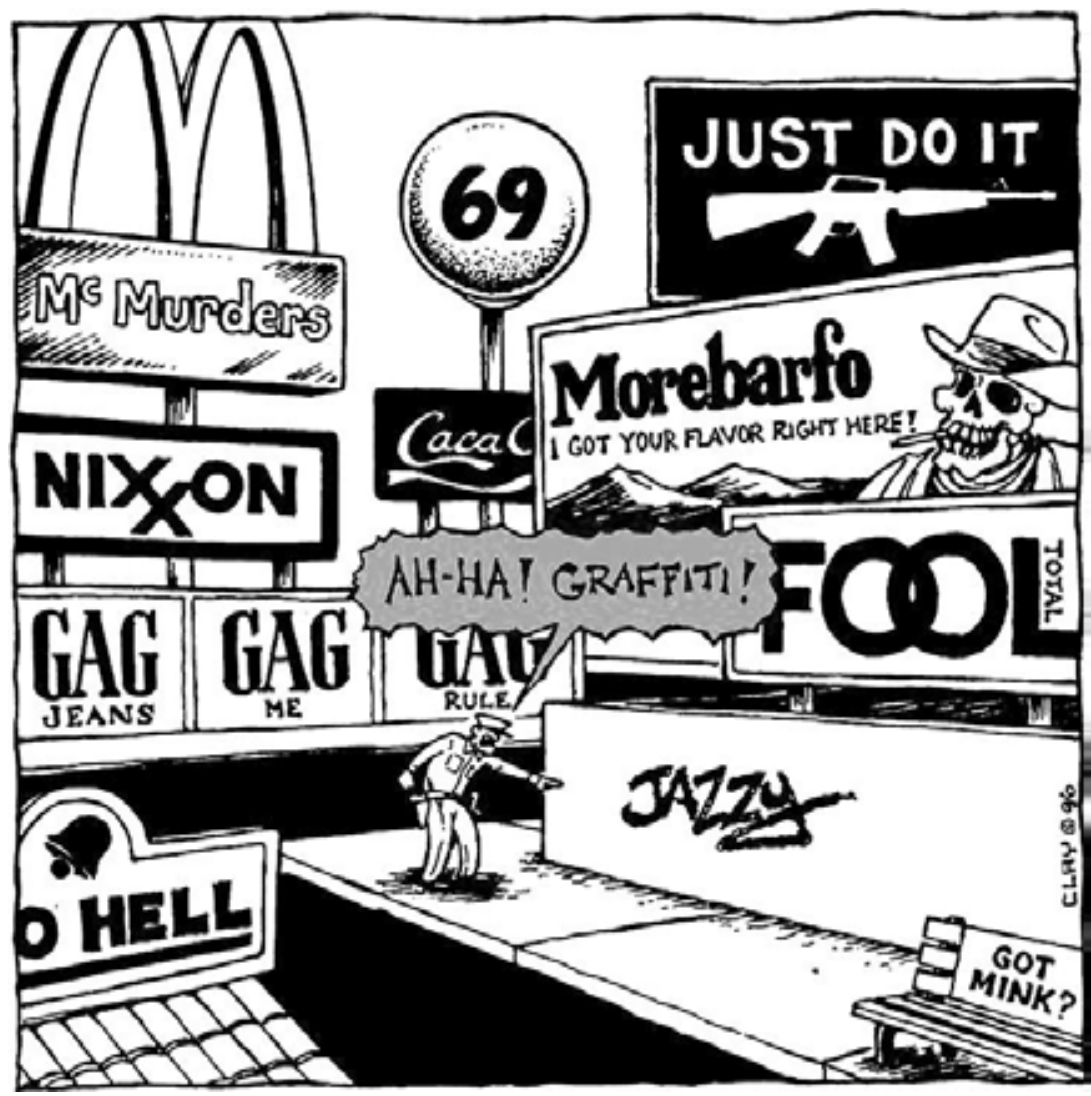

Fuente: Butler (1996).

nes artísticas dentro del crisol multicultural nacional. ${ }^{26}$ Esta normativa se opuso a un acuerdo de 2010, el 291, que prohibía esta expresión en los bienes de uso público y reforzaba la sanción por hacerlo en propiedad privada. Tras la realización de más de trescientas encuestas, la

\footnotetext{
26 El Proyecto de Acuerdo No. 127 de 2011 reza: "Sin duda, Bogotá es una de las ciudades más multiculturales de Colombia. Allí se concentran diversas culturas, razas, religiones, condiciones sociales, etc.; y eso se expresa a través de diversas manifestaciones. Es así que para muchas personas, los grafiti son considerados 'como una manifestación cultural, social y comunicativa que está presente y se involucra de manera activa en el ambiente metropolitano. Por eso es una necesidad indagar sobre su presencia y su función como elemento que expone una idea, una imagen y una concepción del mundo'.
} 
investigación mostró que, para la mayoría de las personas abordadas (68\%), el grafiti constituía un acto agresivo, de vandalismo o era un atentado contra el espacio público, sin importar la regulación, que fueran realizados en los espacios permitidos o que el encuestado fuera informado del Proyecto Acuerdo. ${ }^{27}$

Aquí surge una pregunta obvia: ¿qué tiene que ver todo esto con la discusión sobre el proyecto intercultural? Para responderla (o al menos intentarlo), es pertinente hacer una aclaración: de ninguna manera pretendo caracterizar a los movimientos contraculturales como ejercicios de organización premeditada, con una plataforma de lucha establecida, repertorios de acción delimitados, redes internacionales y estructuras comunicativas; sin embargo, sí es posible identificar lo que algunos autores han denominado "aires de movimiento" (Bosa y Santamaría 2014,), nociones dispersas de organización y acción que apuntan hacia la equivalencia de intereses entre personas y organizaciones con intereses comunes. El punto central aquí es lo que he señalado como la autoproducción de la historicidad y que interpreto como la capacidad de inscribir —en el imaginario y el espacio públicos — el sentido, la versión y "el punto de vista" que estos colectivos tienen de sí mismos y de su entorno. En otras palabras, si parafraseamos la concepción que Homi K. Bhabha (1990) tiene de la historia, las narrativas que producen afiliaciones textuales y sociales en las cuales intervienen discursos que pretenden instalarse como públicos (Restrepo Restrepo, 2005, p. 9). Esas características, digamos estéticas, que he mencionado de los movimientos contraculturales constituyen un ejercicio constante de construir y hacer visibles las narrativas propias, versiones particulares de hechos históricos que han sido tomados como verdades a puño, axiomas insertados en la Historia — con mayúscula— lineal, eurocentrada, capitalista, blanca, machista.

La primera parte de la respuesta a la pregunta anterior, entonces, es que esa producción de historicidad construye un eje central del pro-

\footnotetext{
27 La investigación fue desarrollada por Michela Gómez, estudiante del programa de Relaciones Internacionales. El público objeto de las encuestas se caracterizó por su heterogeneidad: estudiantes, trabajadores, hombres, mujeres, jóvenes, adultos, adultos mayores.
} 
yecto intercultural, en tanto puede servir de articulación de aquellos que son excluidos, al encontrar relatos transversales o poner en diálogo puntos de vista que problematizan y cuestionan las verdades de a puño. Surgen otros interrogantes, como el asunto de la diferencia entre los mismos excluidos. No es un asunto que considere menor y tampoco desconozco lo complicado que, en la práctica, han resultado ejercicios de este tipo. De eso se trata: de que estas líneas sean leídas apenas como apuntes sobre una posibilidad. Sin embargo, tengo dos consideraciones al respecto. En primer lugar, la diferencia no debe matizarse sino radicalizarse:

[...] la única unidad posible no debería erigirse sobre la síntesis de un conjunto de conflictos, sino que habría de constituirse como una manera de mantener el conflicto de modos politicamente productivos, como una práctica contestataria que precisa que estos movimientos articulen sus objetivos bajo la presión ejercida por los otros, sin que esto signifique exactamente transformarse en los otros (Butler, 2000, p. 6).

En segundo lugar, pero no menos importante, se trata de una cuestión de lente. La diferencia entre diferentes - los excluidos del consensono puede desviar la mirada de una cuestión más compleja: las relaciones desiguales estructuradas por la cultura hegemónica. El adversario no está entre los grupos subalternados ni distingue sus diferencias; mejor lo explica La Pestilencia (2001a): "La máquina no prefiere color de piel, la máquina no huele, la máquina no siente. Ella solo te come”.

La primera vez que se mencionó la palabra contracultura fue gracias a un libro del historiador estadounidense Theodore Roszak (1968), quien acuñó ese término para explicar el auge del mundo subterráneo construido por los jóvenes estadounidenses en la década del sesenta. Para entonces, la sociedad de ese país se encontraba en momentos de transición de lo que fue la Segunda Guerra Mundial a lo que la llevaría a constituirse como la cultura hegemónica en casi todo el planeta. Además de un latente sentimiento de patriotismo, una economía que empezaba a resurgir y el contagio de un discurso positivo que invitaba al trabajo juicioso, al consumo, a la defensa del sueño americano y so- 
bre todo al establecimiento de una frontera infranqueable, clausurada: "Estás con nosotros o contra nosotros". Entonces, se produjo la explosión de la cultura pop, definida por Eloy Fernández Porta (2011) como una serie de prácticas artísticas, creativas y expresivas durante la segunda mitad del siglo pasado, que tenía como rasgos principales el público, "generalista o masivo, al estilo de lo imaginado por Adorno y la Escuela de Frankfurt"; el objeto pop, "liviano, sencillo, de acceso inmediato” elaborado para el público masivo; por último, los medios que imponían la inmediatez, el mensaje masivo dotado de un gran simbolismo (en particular patriótico) dirigido a una audiencia "alienada”, por medio de información ligera, fácil de digerir y de máximo entretenimiento (Fernández Porta, 2011).

La cultura pop contribuyó en gran parte a la clausura de la identidad estadounidense de entonces. Por medio del macartismo se apeló a la cohesión de esa sociedad distinguiendo mediante la censura y la autocensura al enemigo, un enemigo amplio en el que cabían desde The Weather Underground con su acción directa contra el Estado (Green y Siegel, 2002) y la autodefensa de las panteras negras, hasta aquellos que en los rincones de las ciudades hacían catarsis y se resistían a la fuerte corriente de la ola pop. El enemigo del sueño americano ya no estaba únicamente en las filas guerrilleras del tercer mundo o detrás de la Cortina de Hierro:

[El] enemigo aparece en el frente interno: todo aquel que disienta con la política exterior del gobierno es perseguido y encarcelado, es un "comunista". Numerosos activistas de los derechos cívicos, intelectuales, escritores, guionistas y artistas de Hollywood ${ }^{28}$ son

\footnotetext{
28 El macartismo, llamado popularmente "cacería de brujas", nació como una intención de identificar y neutralizar las estrategias de espías de la Guerra Fría en el Estado estadounidense. Sin embargo, este se desplazó con rapidez a casi todos los campos de la sociedad; los senadores republicanos pusieron la mira sobre una buena cuenta de personas vinculadas a las artes y al entretenimiento. En una de sus películas más conocidas, Martin Ritt (1976) cuenta la historia de un personaje del estilo looser estadounidense que se convierte en una especie de testaferro en nombre de quien se escriben todos los guiones televisivos de los escritores vinculados a la "lista negra" del macartismo y que, por ende, habían perdido toda posibilidad de trabajo o habían desaparecido.
} 
acusados de antinorteamericanos por el senador Joseph McCarthy (Kreimer y Vega, 2006, p. 4).

La imposibilidad de acceder a espacios públicos para manifestar el malestar respecto a lo que sucedía llevó a crear y recuperar otras formas de significación/representación. Eloy Fernández Porta (2011) recuerda La historia de Sailor y Lula, llevada al cine por David Lynch (1990). En la génesis de la historia, Sailor (un tipo sin muchos capitales ni posibilidades de representación) se pone una chaqueta de cuero de serpiente y le dice a Lula, su novia: "Cariño, ¿te he dicho alguna vez que esta chaqueta simboliza mi independencia?", a lo que ella contesta: "Sí, cariño. Me lo has dicho cien veces". Lo que señala Fernández Porta es la utilización del logo-como-símbolo, la significación de cierto objeto y su uso reiterado: "La relación que se establece entre la [prenda] y su propietario ya no es sólo una relación de identificación literal [...] sino que suele ser desplazada [...] e incluso localizable" (Fernández Porta, 2011, p. 53). De esta manera, una estética particular representa una secuencia de signos (significante/significado) capaz de condensar una serie de discursos, intenciones y sentimientos variados. Así lo relata también Omar Urán al referirse a la estética del punk:

Las cadenas no las usamos para amedrentar a la gente, son un símbolo de presión; los ganchos simbolizan sostener ideas; los zapatos, las botas, son para que duren 2 o 3 años, son una afrenta contra el consumismo de los que creen que la marca hace al joven; las chaquetas las compramos en la plaza minorista o en la salida del anfiteatro, todavía con el olor del muerto fresco, y después las arreglamos a nuestro gusto, el atuendo lo usamos porque nos gusta agredir visualmente a la gente y después escuchar las idioteces que dicen de nosotros (Urán, 1997, citado en Restrepo Restrepo, 2005, p. 10).

Para Stuart Hall (2010), "todos escribimos y hablamos desde un lugar y un momento determinados, desde una historia y una cultura específicas. Lo que decimos siempre está 'en contexto', posicionado [...] todo discurso está 'situado” (p. 349). Aunque con localizaciones geográficas distantes, las equivalencias entre los procesos de signifi- 
cación/representación de los marginados en Estados Unidos (tipo Sailor y todos los "enemigos" del sueño americano) y, por ejemplo, los primeros punks en Medellín (como Urán) son ubicables debido al contexto y la posición que ocupan esos discursos. No pretendo homogenizar los entornos ni sus significantes, aunque sería fácil incurrir en ello no solo por la extrapolación de la estética punk — supuestamente surgida entre Londres y Nueva York- a Colombia. Lo interesante es cómo las verdades de a puño de allí y de acá, producen identidades con interesantes posibilidades de articulación. Recordemos la idea que se exponía en el preludio del artículo, según la cual una identidad no es lo que se dice sobre una persona o un grupo y tampoco lo que esa persona o ese grupo creen ser. La identidad es el producto de esa tensión, en contextos determinados. El movimiento contracultural, como resultado de su propia tensión en Colombia, disloca un metarrelato asociado con la identidad nacional, el progreso y el futuro, para insertar discursos antagónicos en los espacios públicos.

El caso del surgimiento del punk en Medellín lo demuestra. En los años ochenta del siglo anterior, el narcotráfico empezó a consolidarse como una empresa; sus líderes, admirados por los sectores populares, pretendieron trascender en la vida política de la ciudad y del país. La violencia, hasta entonces confinada al espacio rural, se manifestó en los barrios de las ciudades. En Medellín, por ejemplo, cobró fuerza la figura del sicario y se convirtió en una especie de "mensajero del poder", no solo por ser el emisario de los poderosos, sino porque tenía la potestad de decidir quién moría. Los recortes sociales, la falta de oportunidades laborales y una educación de pésima calidad ubicaban a la juventud medellinense en una encrucijada bastante compleja: existía la opción de operar para las estructuras ilegales de poder y la opción de apenas sobrevivir en medio de ese ambiente. Aunado, los jóvenes se encontraron también con que la apuesta política estaba minada por una cruda postura antiizquierdista, que comenzó con la instauración del Estatuto de Seguridad de Julio Cesar Turbay y otorgó un poder casi total a los agentes del monopolio de la violencia. El Estado acosaba; la insurgencia armada secuestraba; la insurgencia política era satanizada; el estilo de vida de los mayores era imposibilitado; el narcotráfico reclutaba y asesinaba. Ante la ausencia de espacios de representación 
formales, la música surgió como alternativa. Sin embargo, el poco rock que sonaba en las emisoras era muy elaborado y solo aquellos jóvenes de las clases sociales acomodadas que viajaban fuera del país podían acceder a los discos, a los libros y a los instrumentos. Además, las letras casi siempre festivas y el estilo elaborado de esas canciones no lograban traducir las tensiones de los sectores populares. Así, "expresiones musicales y culturales como el punk y el metal ofrecieron opciones y refugios de vida para aquellos jóvenes que no quisieron involucrarse directamente con el sicariato y prefirieron afianzar sus vidas con expresiones contraculturales" (Restrepo Restrepo, 2005, p. 17).

Las letras del punk, por ejemplo, recogieron la contrahistoria de la ciudad: los puntos de vista que, de otra manera, no habrían sido conocidos. Se produjo un imaginario colectivo alternativo. Mas esta no es una ecuación sin contradicciones ni problemas; al contrario, la propuesta de discursos marginados y transgresores, mezclada "con el marco social consolidó seres antisociales, depresivos, locos, violentos, desprendidos de todo tipo de prejuicio moral y social”. La falta de esperanza en lo establecido y la rápida identificación con otros jóvenes y subculturas consiguieron lo impensable: "Hacer del caos y la desesperanza una creación, [los punks] le sacaron belleza a la miseria y se inspiraron a través de la violencia $[. .$.$] haciendo de la música$ una territorialidad y una lucha por construir otro mundo" (Restrepo Restrepo, 2005, p. 28).

Se constituye así un compendio de significaciones sociales que entran en contradicción con los discursos públicos, hegemónicos. La crisis de representación política y una cultura nacional que no traduce las subjetividades de ciertos sectores sociales traspasan la pertenencia étnica o un estilo de música particular. La urgencia de construir y situar narraciones alternativas a la historia homogénea y colonial del Estado-Nación colombiano debe servir como excusa como para el diálogo abierto e inclusivo de los más diversos sectores excluidos. Las identidades étnicas y contraculturales son una parte del amplio abanico de subalternidades nacionales. La administración de la diferencia por parte de los Gobiernos nacionales ha profundizado tanto el poder colonial como los abismos entre colectividades. 
¿POR QUÉ ESTUdiAR LOS MOVIMIENTOS SOCIALES HOY? / 161

\section{A modo de apertura}

El contexto no es el telón de fondo, el escenario donde algo sucede, sino sus condiciones de existencia y de transformación. Eduardo Restrepo (2011, p. 14)

Coherente con la propuesta de presentar apuntes que inducen a debates específicos, más que presentar conclusiones me interesa dejar la conversación abierta para ese menester.

Figura 4. Indoor

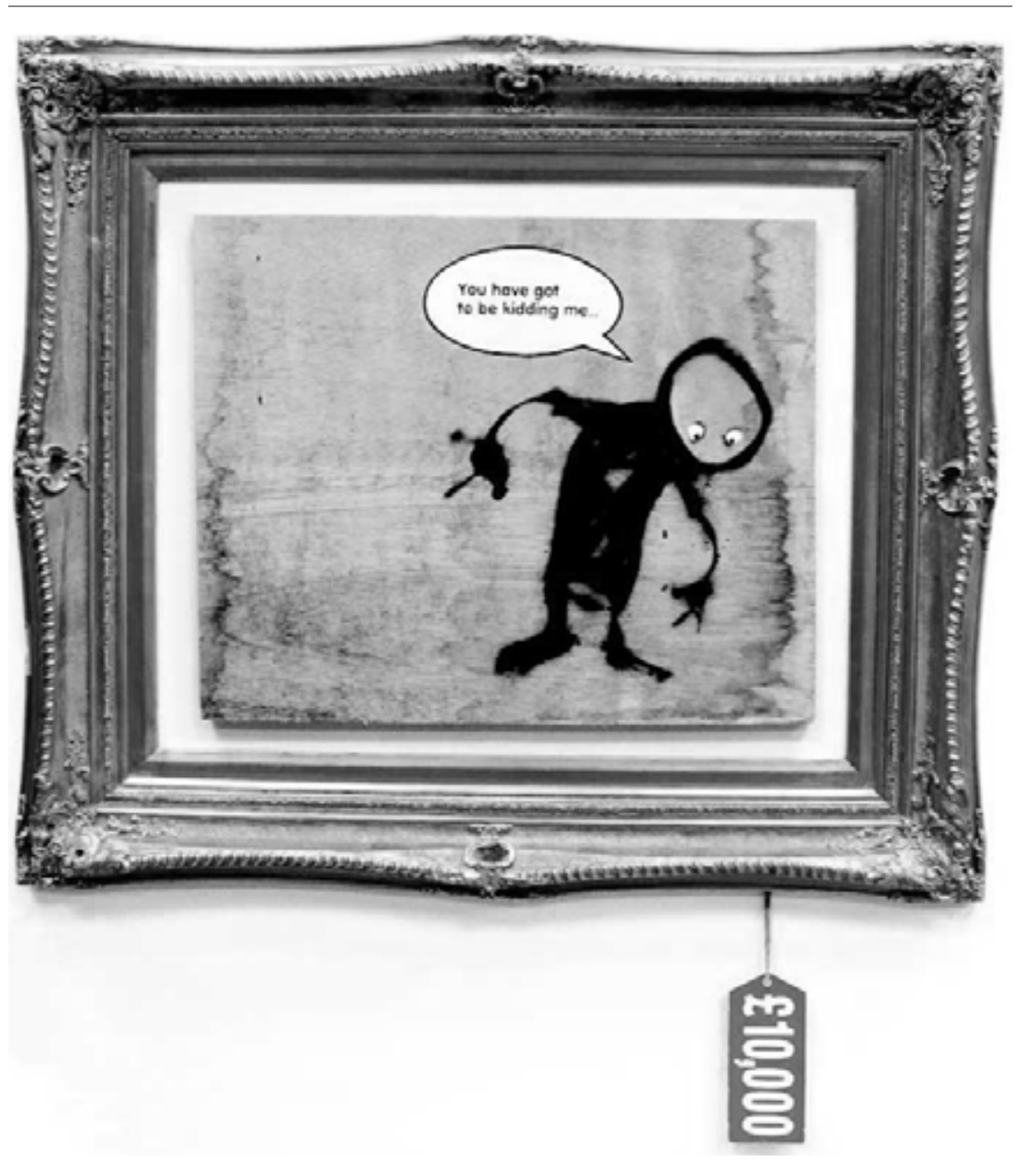

Fuente: Bansky (2006). 
Este artículo deja varios vacíos, en tanto se expusieron algunas ideas que no fueron profundizadas y presentadas con mayor claridad. La ecuación propuesta fue la siguiente: la proliferación de organizaciones sociales étnicas y el trabajo académico cercano a sus procesos de visibilización y empoderamiento han significado un traslape entre etnia y cultura. Esto se aprecia de manera más clara en lo que se ha denominado "proyecto intercultural", que pretende la deconstrucción de los dispositivos de poder y control colonial que, refrescados y tecnificados con la democracia representativa liberal y el sistema económico capitalista, han mantenido y profundizado las relaciones jerárquicas en las que han estado enclaustradas las identidades diferenciadas.

A partir del difuso, poroso y heterogéneo movimiento contracultural, se han mostrado algunos puntos de coincidencia contingente como posibilidades de articulación entre esas identidades subalternadas.

Para ver los alcances y las posibilidades de esa propuesta, se hace necesario un estudio de los NMS con una perspectiva crítica y localizada. Aunque varios autores cercanos a la ciencia política condenan la lógica fragmentadora de los movimientos, su mantenimiento da cuenta de que la crisis de la modernidad no ha sido superada; al contrario, cada vez son más los sectores que no encuentran una significación/representación en los discursos políticos ni en las prácticas culturales habituales.

Ese estudio de los NMS, además de contribuir a la apertura del proyecto intercultural como alternativa política, inscribe las narrativas veladas, las historias no oficiales, en los espacios públicos.

Aunque existen diversos enfoques, acentos y metodologías para estudio crítico y localizado de los NMS, en el trabajo de Stuart Hall sobre las identidades es posible identificar algunos componentes que animan la discusión sobre cómo hacerlo. Para la reconstrucción/ interpretación de esas especificidades de los colectivos, vale la pena echar mano del "contextualismo radical", metodología propia de los estudios culturales que opera en el sentido de campo disciplinario y proyecto político (Grossberg, 2009) y en diferentes planos, porque apunta a un entendimiento complejo de los sujetos de investigación. 
El traslape de este contextualismo entre lo epistemológico, teórico, metodológico y político desborda los límites disciplinarios, para poner en diálogo diversos campos ya no como mero intercambio de datos, sino en la compleja tarea del bricoleur.

En el campo epistemológico, el contextualismo radical se funda en la noción de articulación, es decir:

[...] que las cosas del mundo (prácticas, entidades, ideas, etc.) son resultado de las relaciones que las constituyen [...] estas relaciones son históricamente contingentes y situadas. El conjunto de articulaciones significativas para comprender la especificidad de una cosa en el mundo es la manera en que se define el contexto (Restrepo, 2011, p. 14).

En el plano teórico, el contextualismo apunta a la dislocación de la violencia teórica, entendida como la ilustración de teorías y conceptos planteados de antemano. En cambio, en este plano se visualiza la teorización "como un acto mundanal derivado de las investigaciones concretas y empíricamente orientadas que establecen un constante forcejeo e interrupción de los insumos teóricos con los que cuenta" (Restrepo, 2011, p. 14).

En lo que se refiere a lo metodológico, el contextualismo radical apuesta por el pluralismo que haga ruptura del reduccionismo habitual en una sola disciplina y una sola metodología que cree saber siempre cuál es la respuesta y demuestra que la tiene aun antes de ejecutar la investigación: "Las metodologías y las técnicas de investigación son herramientas que hay que utilizar en función de las preguntas y competencias, sin descartar alguna por simples desautorizaciones disciplinares" (Hall, 2010, p. 14).

Por último, pero con importancia superlativa, está el plano político, ya que el contextualismo radical entiende que una práctica, una concepción o un sujeto no tienen el mismo significado político fuera del contexto que los constituye. La antítesis del contexto es la tesis que constituye al mismo. 
Problematizar, deconstruir y agitar es la tarea de esa perspectiva sentipensante que difumina las fronteras entre lo meramente académico y la acción política. La materialización de un proyecto intercultural es bastante compleja, por la razón de que esas estructuras hegemónicascoloniales han sido elaboradas y activadas con total detalle y energía. Por ello, la articulación de los más diversos sectores se hace urgente y el papel de la academia no es protagónico, pero sí importante. No deben ahorrarse esfuerzos.

La interculturalidad emerge como antítesis a la falacia del "crisol de razas" y la armónica diversidad cultural. Pues bueno: ni crisol de razas, ni amor al prójimo, ni inclusión. Ellos hablan de una sociedad de todos, de respeto, de tolerancia; hacia allá quieren dirigir nuestra atención, pero nosotros, como dice Césaire, hablamos de "millones de hombres a quienes sabiamente se les ha inculcado el miedo, el complejo de inferioridad, el temblor, el ponerse de rodillas, la desesperación, el servilismo". Como dice la canción, "Ese mundo perfecto aquí nunca llegó" (La Pestilencia, 2001b).

\section{Referencias bibliográficas}

Andrade, O. (1928). Manifiesto antropófago. Recuperado de http://www.ccgsm. gov.ar/areas/educacion/cepa/manifiesto_antropofago.pdf

Ascoba. (2010). Palmo a palmo (6). Recuperado de http://www.ascoba.org. co/palmo-a-palmo/ver-categoria.html

Balitti, O. (2007). El poder de uno. Recuperado de http://www.taringa.net/ posts/imagenes/15300610/19-Fotos-que-obtuvieron-el-premioPulitzer.html

Bansky, (2006). Indoor. Recuperado de http://iheartartblog.files.wordpress. com/2011/12/kiddingme2.jpg

Bhabha, H. (1990), Nación y narración. Buenos Aires: Siglo XXI editores.

Boikot. (2000). Korsakov. En Historias directas de Boikot [CD]. Madrid: Zero Records.

Bosa, B., y Santamaría, Á. (mayo 2, 2014). Notas de campo de la presentación en el Seminario experimental del Doctorado en Estudios Políticos e Internacionales de la Universidad del Rosario. 
Bueno, G. (1992). ¿Qué queremos decir cuando hablamos de cultura? Recuperado de http://www.fgbueno.es/hem/1992b08.htm

Butler, C. (1996). Graffiti. Recuperado de http://31.media.tumblr.com/ 2229a6bdf4451151c134aee121748886/tumblr_mkdk9db5zI1qz778zo1_1280.jpg

Butler, J. (2000). El marxismo y lo meramente cultural. New Left Review, (2), 109-121.

Calderón, L. M. (2012). Análisis del proceso de las redes transnacionales que protegen a defensores de derechos humanos. Caso: Resolución de la CIDH, medidas provisionales respecto a la República de Colombia, asunto Mery Naranjo y otros (2006-2011). Recuperado de http:// repository.urosario.edu.co/bitstr eam/10336/3986/1/1020733128-2012.pdf

Cante, F. (2007). Acción colectiva, metapreferencias y emociones. Cuadernos de economía, 26 (47), 151-174.

Cante, F. (2010). Libertades individuales y acción colectiva. Bogotá: Universidad del Rosario.

Castro-Gómez, S. (2007). Decolonizar la universidad. La hybris del punto cero. En: S. Castro-Gómez y Grosfoguel. El giro decolonial. Reflexiones para una diversidad espistémica más allá del capitalismo global (pp. 79-92). Bogotá: Instituto Pensar-IESCO-Siglo del Hombre Editores.

Cinep. (1986). Los movimientos cívicos. Bogotá: Cinep.

Cohen, J. (1985). Strategy of Identity: New Theoretical Paradigms and Contemporary Social Movements. Social Research, 52 (4), 663-716.

Congreso de los Pueblos. (2013). ¿Qué es el Congreso de los Pueblos? Recuperado de http:/ / congresodelospueblos.org/index.php/caminando-al-cnttscongreso-nacional-de-tierras-territorios-y-soberanias/congreso

Control Machete. (2003). Cómo ves. En Uno, dos, bandera [CD]. México D. F.: Universal Music.

Della Porta, D., y Kriesi, H. (2002). Social Movements in a Globalization World. Nueva York: Macmillan.

Durán, A. (2008). Políticas de lugar en los movimientos sociales contemporáneos. Diálogos Latinoamericanos, (14), 57-75.

Escobar, A. (1997). Biodiversidad, naturaleza y cultura: localidad y globalidad en las estrategias de conservación. México D. F.: UNAM.

Escobar, A. (2003). Mundos y conocimientos de otro modo. El programa de investigación de modernidad/colonialidad latinoamericano. Tabula Rasa, (1), 51-86. 
Escobar, A. (2005). Más allá del tercer mundo. Globalización y diferencia. Bogotá: Instituto Colombiano de Antropología e Historia.

Escobar, A. (2012). Gran minería: desarrollo y crisis del modelo neoliberal en América Latina. Taller Revista de análisis de la actualidad política, (29), 95-101.

Escobar, A., y Pedrosa, Á. (1996). Pacífico: ¿desarrollo o diversidad? Bogotá: Cerec.

Fernández E. (2011). Cultura After Pop/Entrevistador: Liberatorio contemporáneo. Recuperado de http:/ / www.youtube.com/watch?v=Bu9x9-15KBg

Flórez-Flórez, M. J. (2007). Lectura no eurocéntrica de los movimientos sociales latinoamericanos. Las claves analíticas del proyecto modernidad/colonialidad. En S. Castro-Gómez y R. Grosfoguel (eds.), El giro decolonial. Reflexiones epistémicas más allá del capitalismo global (pp. 243-266). Bogotá: Instituto Pensar.

Fukuyama, F. (1992). El fin de la historia y el último hombre: la interpretación más audaz y brillante de la historia presente y futura de la humanidad. Bogotá: Planeta.

Green, S., y Siegel, B. (productores y directores) (2002). The Weather Underground. [Película]. Nueva York: Docurama.

Gressemberg, L. (2009). Stuart Hall sobre raza y racismo: Estudios culturales y la práctica del contextualismo. Tábula Rasa, (5), 45-65.

Goffman, K. (2005). La contracultura a través de los tiempos. De Abraham al acidhouse. Madrid: Anagrama.

Guache Street Art. (2011). Oxidente des-orientado. Recuperado de http:/ / www. flickr.com/photos/proun/sets/72157628033554848/

Hall, S. (2010). Sin garantías. Trayectorias y problemáticas en estudios culturales. Quito: Universidad Andina Simón Bolívar.

Haraway, D. ([1991] 2013). Un manifiesto cyborg. Recuperado de http:// www.icesi.edu.co/blogs/antro_conocimiento/files/2012/02/Haraway_MANIFIESTO-CYBORG.pdf

Heath y Poter (2005). Rebelarse vende: el negocio de la contracultura. Bogotá: Alfaguara.

HHR Colectivo (2010). Manifiesto Epatu. Recuperado de http:/ / epatutatuy. blogspot.com/

Keck, M. E., y Sikkink, K. (2000). Activistas sin fronteras. Bogotá: Siglo XXI. Kreimer, J. C., y Vega, F. (2006). Contracultura para principiantes. Buenos Aires: Era Naciente. 
La Pestilencia. (2001a). Carne molida. En Balistica [CD]. Los Ángeles: Universal.

La Pestilencia. (2001b). Soñar despierto. En Balistica [CD]. Los Ángeles: Universal.

Laclau, E. (2005). La construcción del pueblo. En La razón populista (pp. 99130). Buenos Aires: Fondo de la Cultura Económica.

Lander, E. (2000). ¿Conocimiento para qué? ¿Conocimiento para quién? En S. Castro-Gómez (ed.), La reestructuración de las ciencias sociales en América Latina (pp. 90-126). Bogotá: Instituto Pensar.

Le Bon, G. ([1894] 1983). Psicología de las masas. Madrid: Morata.

Marroquin, E. (1975). La contracultura como protesta. México: Editorial Joaquin Moritz.

Martínez, G. (2012). El concepto de CT. En G. Martínez (coord.), CT o la Cultura de la Transición (pp. 13-24). Barcelona: Debolsillo.

Medina Reyes, E. (2003). Érase una vez el amor pero tuve que matarlo (música de Sex Pistols y Nirvana). Bogotá: Planeta.

Melucci, A. ([1976] 1985). Las teorías de los movimientos sociales. Revista de Estudios Politicos, (93), 92-101.

Minchinela, R. (2012). La CT y la cultura digital: cómo dar la espalda a internet. En G. Martínez (coord.), CT o la Cultura de la transición (pp. 151-160). Barcelona: Debolsillo.

Mouffe, C. (1999). El retorno de lo político. Barcelona: Paidós.

Naranjo, É. R. (2012). De la lucha por la tierra al reconocimiento de los derechos humanos: genealogía discursiva del Consejo Regional Indígena del Cauca. En Á. Santamaría y P. Rojas, Identidades políticas porosas. Estudios sobre las reivindicaciones sociales nacionales y transnacionales (pp. 131-186). Bogotá: Universidad del Rosario.

Organizaciones participantes (1995). Declaración política del encuentro de organizaciones sociales de Colombia. Bogotá: Cinep.

Pardo, M. (1997). Movimientos sociales y actores no gubernamentales. En E. Restrepo y M. V. Uribe editores académicos.), Antropología en la modernidad (pp. 70-94). Bogotá: Instituto Colombiano de Antropología.

Rendón, M. A., y Saade, J. (2013). La Mesa Amplia Estudiantil de la contrarreforma al reflujo: ¿es la MANE necesaria en el debate de la educación superior? (2011-2013). 
Manuscrito inédito, Seminario de investigación Movimientos Sociales y Luchas Políticas, Universidad del Rosario, Bogotá, Colombia.

Restrepo, E. (2005). Biopolítica y alteridad: dilemas de la etnización de las Colombias negras. En E. Restrepo, Políticas de la teoría y dilemas en los estudios de las Colombias negras (pp. 143-167), Popayán: Universidad del Cauca.

Restrepo, E. (2011). Estudios culturales y educación: posibilidades, urgencias y limitaciones. En K. Saraiva y F. de Amorim Marcello (eds.), Estudios culturais e edicaçao: desafíos atuais (pp. 87-99). Canoas: Ulbra.

Restrepo, E. (2012). Antropologías disidentes. Cuadernos de antropología social, (35), 55-69.

Restrepo, E. (2012). Intervenciones en teoría cultural. Popayán: Universidad del Cauca.

Restrepo, E. (2012a). Antropologías disidentes. Cuadernos de Antropología Social, (35), 55-69.

Rodríguez, A. C., Rojas-Oliveros, P., y Santamaría, Á. (2012). Introducción. En Rojas y Santamaría et al. Identidades políticas porosas (pp. xiii-xxxiii). Bogotá: Universidad del Rosario.

Rodríguez, C. (2009). Prólogo. En: Lemaitre, J. El derecho como conjuro (pp. 17-21). Bogotá: Universidad de los Andes.

Rodríguez Garavito, C., y De Soussa Santos, B. (eds.) (2003). Law and Globalization from Below: Toward a Cosmopolitan Legality. Cambridge: Cambridge University Press.

Rodríguez Garavito, C., y García Villegas, M. (2005). Derecho y sociedad en América Latina. Bogotá: ILSA.

Rojas, A. (2011). Gobernar(se) en nombre de la cultura. Interculturalidad y educación para grupos étnicos en Colombia. Revista Colombiana de Antropología, 47 (2), 173-198.

Romero Ramírez, L. (2013). Análisis de la incidencia del principio de neutralidad en la conformación de las redes transnacionales de defensa de las zonas bumanitarias y de biodiversidad de Curvaradó y Jiguamiandó (1997-2003). Recuperado de http:// repository.urosario.edu.co/bitstre am/10336/4345/1/1020739470-2013.pdf

Roszack, T. (1968). El nacimiento de una contracultura: reflexiones sobre la sociedad tecnocrática y su oposición juvenil. Barcelona: Kairós.

Santamaría, Á. (2008). Redes transnacionales y emergencia de la diplomacia indígena: un estudio del caso colombiano. Bogotá: Universidad del Rosario. 
Santamaría, Á. (2013). Lorenzo Muelas y el constitucionalismo indígena ¿desde abajo?: una retrospectiva crítica sobre el proceso constituyente de 1991. Colombia Internacional, (79), 77-120.

Segato, R. (2007). La Nación y sus otros. Raza, etnicidady diversidad religiosa en tiempos de Políticas de la Identidad. Buenos Aires: Prometeo.

Smelser, N. (1962). The Theory of Collective Behavior. Nueva York: Free Press. Tarrow, S. (2005). El poder en movimiento. Madrid: Alianza.

Tilly, C. (1984). Social Movements and National Politics. En W. Bright y S. Harding (eds.). State Building and Social Movements (pp. 34-58). Ann Arbor: University of Michigan Press.

Touraine, A. (2006). Los movimientos sociales. Revista colombiana de Sociología, (27), 255-278.

Trouillot, M. -R. (2011). Transformaciones globales. La antropología y el mundo moderno. Popayán: Universidad del Cauca.

Turner, R. G., y Killian, L. M. (1957). Collective Behavior. Englewood Cliffs: Prentice Hall.

Ultrágeno. (2002). Código fuente. En Código fuente [CD]. Bogotá: MTM.

Varese, S. (1996). Parroquialismo y globalización. Las etnicidades indígenas ante el tercer milenio. En S. Varese (coord.), Pueblos indígenas, soberanía y globalismo (pp. 122-142). Quito: Abya-Yala.

Wallerstein, E. (1996). Abrir las ciencias sociales. Madrid: Siglo XXI Editores.

Walsh, C. (2007). Interculturalidad, colonialidad y educación. Educación y Pedagogía, XIX (48), 25-35.

Walsh, C. (2010). Interculturalidad crítica y educación intercultural. En J. Viaña, L. Tapia, y C. Walsh (eds.), Construyendo interculturalidad crítica. La Paz: Instituto Internacional de Integración del Convenio Andrés Bello.

Zizek, S. (1998). Multiculturalismo, o la lógica cultural del capitalismo multinacional. En F. Jameson, y S. Zizek (eds.), Estudios culturales. Reflexiones sobre el multiculturalismo. Buenos Aires: Paidós.

Zizek, S. (comp.) (2003). Todo lo que usted siempre quiso saber sobre Lacan y nunca se atrevió a preguntarle a Hitchcock. Buenos Aires: Manantial.

Zizek, S. (2007). En defensa de la intolerancia. Buenos Aires: Sequitur. 
